\title{
Anti-inflammatory effects of androgens in the human vagina
}

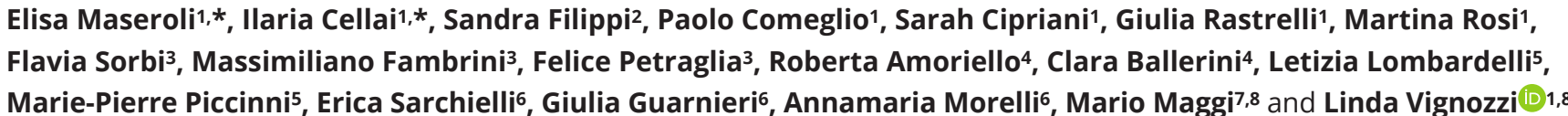

'Andrology, Women's Endocrinology and Gender Incongruence Unit, Department of Experimental Clinical and Biomedical Sciences 'Mario Serio', University of Florence, Florence, Italy

2Interdepartmental Laboratory of Functional and Cellular Pharmacology of Reproduction, Department of Neurosciences, Psychology, Drug Research and Child Health (NEUROFARBA), University of Florence, Florence, Italy

3Gynecology Unit, Department of Biomedical, Experimental and Clinical Sciences 'Mario Serio', University of Florence, Florence, Italy ${ }^{4}$ Department of Neurosciences, Psychology, Drug Research and Child Health (NEUROFARBA), University of Florence, Florence, Italy ${ }^{5}$ Department of Experimental and Clinical Medicine, University of Florence, Florence, Italy

${ }^{6}$ Section of Human Anatomy and Histology, Department of Experimental and Clinical Medicine, University of Florence, Florence, Italy 7Endocrinology Unit, Department of Experimental Clinical and Biomedical Sciences 'Mario Serio', University of Florence, Florence, Italy

8I.N.B.B. (Istituto Nazionale Biostrutture e Biosistemi), Rome, Italy

Correspondence should be addressed to L Vignozzi: linda.vignozzi@unifi.it

*(E Maseroli and I Cellai contributed equally to this work)

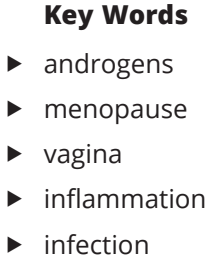

Key Words

Chronic inflammation is involved in the genitourinary syndrome of menopause (GSM) and beneficial effects of androgens in the vagina have been described. We investigated the potential involvement of human vagina smooth muscle cells (hvSMCs) in the inflammatory response and the immunomodulatory effect of androgen receptor (AR) agonist dihydrotestosterone (DHT). HvSMCs isolated from menopausal women were evaluated for sex steroids receptors and toll-like receptors mRNA expression, and left untreated or treated in vitro with lipopolysaccharide (LPS) or IFN $\gamma$, in the presence or absence of DHT. We evaluated mRNA expression (by RT-PCR) and secretion in cell culture supernatants (by a bead-based immunoassay) of pro-inflammatory markers. Nuclear translocation of NF-кB (by immunofluorescence) and cell surface HLA-DR expression (by flow cytometry) were also evaluated. Similar experiments were repeated in rat vSMCs (rvSMCs). In hvSMCs and rvSMCs, AR was highly expressed. DHT pre-treatment inhibited LPS-induced mRNA expression of several pro-inflammatory mediators (i.e. COX2,

$I L-6, I L-12 A$ and $I F N \gamma)$, effect significantly blunted by AR antagonist bicalutamide. DHT significantly counteracted the secretion of IL-1RA, IL-2, IL-5, IL-15, FGF, VEGF and TNF $\alpha$. LPS-induced NF-kB nuclear translocation was significantly inhibited by DHT, an effect counteracted by bicalutamide. DHT pre-treatment significantly decreased IFN $\gamma$-induced expression of HLA-DR, mRNA expression of iNOS, COX2 and MCP1, and secretion of IL-1, IL-2, IL-5, IL-6, MCP1 and GCSF. Similar effects were observed in rvSMCs. The activation of AR suppresses the inflammatory response in hvSMCs, reducing their potential to be involved in the initiation and maintaining of inflammation, thus representing a therapeutic strategy in conditions, such as the GSM.
Journal of Molecular Endocrinology (2020) 65, 109-124 


\section{Introduction}

For some women, menopause is an asymptomatic and unremarkable life transition, but for others it is accompanied by severe symptoms, such as hot flushes, mood changes and the so-called genitourinary syndrome of menopause (GSM), affecting approximately 50\% of middle-aged and elderly women (Portman \& Gass 2014). GSM construct encompasses a plethora of clinical manifestations, including vulvovaginal atrophy and lower urinary tract symptoms (LUTS) (Simon et al. 2018), which can impair quality of life by exerting detrimental effects on sexual health and general well-being (Simon et al. 2018).

The primary cause of GSM is a substantial and rapid drop of estrogen levels at menopause. However, a decline in androgen level is also likely to play a pathogenic role in the onset of GSM (Simon et al. 2018). Indeed, both changes in the genitourinary system and a progressive decline of circulating levels of total testosterone have been described in women throughout the aging process (Zumoff et al. 1980, Davison et al. 2005). Moreover, the androgen receptor (AR) is widely expressed in structures derived from the urogenital sinus, such as distal vagina, urethra and bladder, not only during embryogenesis (Cunha et al. 2017) but also throughout the adult life (Vignozzi et al. 2012a). Accordingly, several pre-clinical and clinical evidence indicates that androgens play a crucial role in the maintenance of genitourinary tissue structure and function in adulthood (Vignozzi et al. 2012a, Comeglio et al. 2016, Simon et al. 2018).

Adding layer to this complexity, chronic inflammation is a subtle underlying factor of GSM symptoms. The vaginal innate immune system is a unique and complex immunologic environment. Through an intricate balance among its major components, it is able to defend the genitourinary tract against pathogens, while maintaining immune-homeostasis and avoiding chronic inflammatory/autoimmune diseases. To accomplish this role, the human vagina contains several resident professional antigen presenting cells (APCs) (i.e. macrophages and dendritic cells) that recognize specific key molecules on the surface of pathogens, such as lipopolysaccharide (LPS), through the tolllike receptors (TLRs) system (Fazeli et al. 2005). Such recognition leads to pathogen clearance, leukocyte recruitment and antigen presentation to lymphocytes (Fazeli et al. 2005). Activation of TLRs is followed by a sustained release of proinflammatory cytokines and chemokines, including interleukin (IL) $1 \beta$ (IL-1 $\beta$ ), IL-6, tumor necrosis factor- $\alpha(\mathrm{TNF} \alpha)$, and chemokine (C-X-C motif) ligand 8 (CXCL8) (Pivarcsi et al. 2005). This acute response to infectious agents, to which the lower female genitourinary tract is particularly exposed, normally acts by removing the pathogens and initiating the healing process, leading to the restoration of tissue homeostasis. However, when resolution of the inflammation fails, chronic autoimmune inflammatory process may occur, as a result of uncontrolled differentiation and expansion of autoreactive CD4+ T helper (Th) cells, Th1 (Chen et al. 2017b).

Interestingly, in experimental models of chronic inflammatory diseases, androgens have shown prominent immunomodulatory and protective effects. In particular, in an experimental animal model of metabolic syndrome, testosterone treatment counteracted the chronic, multiorgan inflammation within the liver (Vignozzi et al. 2014), skeletal muscle (Sarchielli et al. 2020), and lower genitourinary tract tissues (Morelli et al. 2012, Vignozzi et al. 2012b). Noteworthy, in human prostatic stromal cells (Penna et al. 2009, Fibbi et al. 2010, Vignozzi et al. 2012c, 2013a,b, Comeglio et al. 2014), a well-validated non-professional APCs model, in vitro treatment with the selective AR agonist dihydrotestosterone (DHT) counteracted the expression and secretion of a plethora of cytokines and chemokines, induced by TNF $\alpha$ and LPS (Fibbi et al. 2010, Vignozzi et al. 2012a, 2013a,b). Although deep similarities in biological and molecular processes of male and female urogenital tracts have been demonstrated (Vignozzi et al. 2012c,d, Comeglio et al. 2016), the potential role of androgen-based therapies in the modulation of chronic genital inflammation in women has not been explored yet.

Present study is aimed at investigating, in human distal vagina smooth muscle cells (hvSMCs) isolated from post-menopausal women: (1) the expression of sex steroids receptors, in particular the AR, and of TLRs, which are usually expressed on resident APCs; (2) their potential involvement in the inflammatory response, acting as non-professional APCs and secreting a variety of proinflammatory mediators; (3) a possible anti-inflammatory effect of the selective AR agonist dihydrotestosterone (DHT). Similar experiments were also replicated in primary cell cultures derived from female rat distal vaginal tissues (rvSMCs) to evaluate possible species-specific differences. Our working hypothesis is that, similar to what previously demonstrated in the male genital tract (Vignozzi et al. 2012a), androgens might negatively modulate the inflammatory response in the vagina. 


\section{Materials and methods}

\section{Surgical procedures and collection of biological samples}

Human vagina and ovary tissues were obtained, after informed consent, from post-menopausal women undergoing surgery for benign gynecological disorders (study approved by the Ethics Committee 'Area Vasta Centro', Azienda Ospedaliero Universitaria Careggi, Florence, Italy: HUMVAGDHT, protocol no. 12903). Specifically, specimens from the upper third of the distal vagina, measuring approximately $3 \times 1 \mathrm{~cm}$, were collected.

Sprague-Dawley female rats $(n=5$; Envigo, San Pietro al Natisone, Udine, Italy), weighting approximately 250 $\mathrm{g}$, were individually caged under standard conditions in a temperature- and humidity-controlled room on a $12 \mathrm{~h}$ light:12 $\mathrm{h}$ darkness cycle, with free access to water and food throughout the study. After 8 weeks, the animals were killed by cervical dislocation, and the distal vagina and other tissues were collected for subsequent analysis. Animal handling complied with the Institutional Animal Care and Use Committee (IACUC) of the University of Florence, Italy, in accordance to the Italian Ministerial Law no. 26/2014.

\section{Human and rat vagina smooth muscle cell cultures}

Human smooth muscle cells (hvSMCs) were isolated from vaginal tissues and preliminary experiments were performed to validate the experimental protocol. Similarly, rat smooth muscle cells (rvSMCs) were isolated from distal vagina obtained from intact control female rats. The tissues biopsies were processed by mechanical and enzymatic dissection as previously described (Granchi et al. 2002, Comeglio et al. 2016). Briefly, single vagina tissue samples were digested with bacterial collagenase type IV ( $2 \mathrm{mg} / \mathrm{mL}$; Worthington Biochemical Corporation, Lakewood, NJ, USA) overnight at $37^{\circ} \mathrm{C}$, the fragments were washed in PBS and centrifuged at $380 \boldsymbol{g}$ for $10 \mathrm{~min}$, the pellet was recovered and cultured in growth medium (GM) DMEM and Ham F-12 medium (DMEM/F12 1:1; Sigma-Aldrich) red phenol free supplemented with $10 \%$ fetal bovine serum (FBS; Sigma-Aldrich), antibiotics (penicillin $100 \mathrm{IU} / \mathrm{mL}$, streptomycin $100 \mathrm{mg} / \mathrm{mL}$; SigmaAldrich), and amphotericin B (1 mg/mL; Sigma-Aldrich) in a fully humidified atmosphere of $95 \%$ air and $5 \% \mathrm{CO}_{2}$. SMCs began to emerge within $48 \mathrm{~h}$ and were used until the seventh/eighth passage.

For cytokines and chemokines mRNA expression analyses, hvSMCs and rvSMCs were seeded onto six-well plates $\left(1.5 \times 10^{5}\right.$ cells/well) in GM. After overnight serum starvation, the cells were left untreated (NT) or pre-treated with dihydrotestosterone (DHT, $30 \mathrm{nM}$; Sigma-Aldrich) with or without the non-steroidal antiandrogen bicalutamide (BICA, $1 \mu \mathrm{M}$; Sigma-Aldrich) for $24 \mathrm{~h}$ and then stimulated with LPS $(100 \mathrm{ng} / \mathrm{mL})$ or interferon $\gamma$ (IFN $\gamma 1000 \mathrm{UI} / \mathrm{mL}$; R\&D Systems) for $24 \mathrm{~h}$. In preliminary experiments, the effect of LPS stimulation was tested on SMCs by time course experiments ( $24 \mathrm{~h}$ and $48 \mathrm{~h}$ ) to identify the optimal inflammatory activity of LPS, using IL-6 and IL-8 expression as a readout (data not shown). The DHT concentration of $30 \mathrm{nM}$ was selected as it was demonstrated to represent the physiological concentration of DHT within the human prostate (Marks et al. 2006) able to completely block TNFo-, LPS-, or activated CD4+ T-cell-induced inflammatory response in myofibroblast hBPH cells (Vignozzi et al. 2012a). All the experiments were performed in triplicate in at least three different cell preparations.

\section{Immunohistochemistry cell characterization}

The SMC nature of cell cultures was characterized as previously described (Comeglio et al. 2016). Briefly, hvSMCs and rvSMCs were seeded at the density of $1 \times 10^{4}$ cells on glass coverslips in GM and left untreated until complete cell adhesion. They were then immunostained using specific smooth muscle markers myosin heavy chain 11 mouse MAB (MHC11, 1:200, v/v; Abcam) and $\alpha$ smooth muscle actin ( $\alpha$ SMA, 1:100 vol/vol; Sigma-Aldrich). The immunostaining for the epithelial marker cytokeratin C (pre-diluted mouse MAB; Ventana Medical System, Oro Valley, AZ, USA) was taken as negative control.

For androgen receptor (AR) detection, immunocytochemical studies were performed as previously described (Comeglio et al. 2016). Briefly, cells were fixed in $2 \%$ paraformaldehyde, followed by permeabilization with $0.1 \%$ Triton X-100 and blocking with $1 \%$ BSA. In rvSMCs the immunostaining was performed with anti-androgen receptor mouse MAB (1:50, v/v; Santa Cruz Biotechnology) followed by Alexa Fluor 488 goat anti-mouse IgG $(\mathrm{H}+\mathrm{L})(1: 200, \mathrm{v} / \mathrm{v}$; Invitrogen Molecular Probes). In hvSMCs the anti-androgen receptor rabbit polyclonal antibody (1:50, v/v; Santa Cruz Biotechnology) was used followed by Alexa Fluor 568 goat anti-rabbit $\operatorname{IgG}(\mathrm{H}+\mathrm{L})$ secondary antibody $(1: 200, \mathrm{v} / \mathrm{v}$; Invitrogen Molecular Probes). Antibody specificity was verified by omitting the primary antibody. 


\section{Immunofluorescence microscopy}

The rvSMCs and hvSMCs were seeded at the density of $1 \times 10^{4}$ cells on glass coverslips in GM. After overnight serum starvation, cells were left untreated (NT) or incubated with DHT (30 nM) in the presence or absence of BICA $(1 \mu \mathrm{M})$ for $24 \mathrm{~h}$, then stimulated with LPS $(100 \mathrm{ng} / \mathrm{mL})$ for $5 \mathrm{~h}$.

Immunostaining was performed as previously described (Penna et al. 2009) using a primary mouse MAB against NF-кB p65 (1:100, v/v; Santa Cruz Biotechnology) followed by Alexa Fluor 488 goat anti-mouse conjugated secondary antibody (1:200, v/v; Invitrogen Molecular Probes). Slides were then examined with a phase contrast microscope (Microphot-FX microscope, Nikon). Experiments were performed three times with three different cell preparations.

\section{Analysis of cytokines and chemokines production by hvSMCs cells}

The hvSMCs were seeded onto six-well plates in $1 \mathrm{~mL}$ of GM $\left(1.5 \times 10^{5}\right.$ cells/well $)$ and after overnight serum starvation they were left untreated (NT) or were pretreated for $24 \mathrm{~h}$ with DHT (30 nM), in the presence or absence of BICA $(1 \mu \mathrm{M})$, and then stimulated with LPS $(100 \mathrm{ng} / \mathrm{mL})$ or IFN $\gamma(1000 \mathrm{UI} / \mathrm{mL})$ for further $24 \mathrm{~h}$. Cell culture supernatants were collected and analyzed according to the manufacturer's instructions (Bio-Rad Laboratories).

A bead-based multiplex immunoassay (Bio-Rad Laboratories) and a Bioplex 200 system (Luminex Map Technology, Bio-Rad Laboratories) were used to simultaneously measure the concentrations of the following cytokines and chemokines in cell culture supernatants (IL-1 $\beta$, IL-1RA, IL-2, IL-4, IL-5, IL-6, IL-8, IL-9, IL-10, IL-12, IL-13, IL-15, IL-17A, IFN $\gamma$, TNF $\alpha$, GCSF (granulocyte-colony-stimulating factor), GMCSF (granulocyte-macrophage colony-stimulating factor), VEGF (vascular endothelial growth factor), PDGF (platelet-derived growth factor), FGF (fibroblast growth factor), IP10 (interferon-inducible protein 10), MCP1 (monocyte chemoattractant protein-1), RANTES (regulated on activation, normal $\mathrm{T}$ cell expressed and secreted), MIP1A and MIP1B (macrophage inflammatory protein 1-alpha and 1-beta)). Briefly, $50 \mu \mathrm{L}$ of supernatant were added to $50 \mu \mathrm{L}$ of antibody-conjugated beads directed against the analytes listed above in a 96-well filter plate. After a 30-min incubation, the plate was washed and the biotinylated anti-cytokine antibody solution was added to each well. The plate was then washed and streptavidin-conjugated phycoerythrin (PE) was added to each well. After a final wash, the plate was analyzed with the Bioplex 200 system. Standard curves were derived from various concentrations of the different cytokine standards in the assay and followed the same protocol as the supernatant samples. The concentration of each cytokine $(\mathrm{pg} / \mathrm{mL})$ in each supernatant was then calculated by Bioplex software (Bio-Rad Laboratories) and normalized by the relative cell count. The assay sensitivity for all proteins tested was $<1 \mathrm{pg} / \mathrm{mL}$.

\section{Flow cytometry}

The hvSMCs were seeded onto $60 \mathrm{~mm}$ plates $\left(2 \times 10^{5}\right.$ cells/well) in $3 \mathrm{~mL}$ of $\mathrm{GM}$ and after serum starvation cells were pre-treated for $24 \mathrm{~h}$ with DHT $(30 \mathrm{nM})$ and thereafter stimulated with IFN $\gamma(1000 \mathrm{UI} / \mathrm{mL})$ for $48 \mathrm{~h}$. Untreated cells (NT) were used, as control. The hvSMCs were detached by trypsin (Sigma-Aldrich) and after centrifugation $1 \times 10^{5} / \mathrm{mL}$ cells for each experimental point were counted and immunolabeled with HLA-DR (PE) $(1: 10, \quad \mathrm{v} / \mathrm{v} ; \quad \mathrm{BD}$ Biosciences PharMingen) for $15 \mathrm{~min}$ at room temperature. Unlabelled cells were used as negative control. Flow cytometric acquisition was performed by collecting $1 \times 10^{4}$ events on a FACScalibur (BD Biosciences) or on Epics XL-System II flow cytometer (Beckman Coulter), and data were analyzed as previously described (Urbani et al. 2006).

\section{Real-time quantitative reverse transcriptase polymerase chain reaction}

Isolation of RNA from tissues was performed by solubilizing with TRIzol reagent (Life Technologies) and using chloroform thus obtaining an aqueous solution of nucleic acids.

The primary cultures smooth muscle cells were processed utilizing the a commercial RLT lysis buffer (Qiagen). Total RNA extraction for both tissues and cells was finally obtained by purification of the aqueous solutions using the RNeasy Mini Kit (Qiagen), according to the manufacturers' instructions.

cDNA synthesis was carried out using the iScript ${ }^{\mathrm{TM}}$ cDNA Synthesis Kit (Bio-Rad Laboratories). Quantitative real-time quantitative RT-PCR amplification and detection were carried out using SsoAdvanced Universal Probes Supermix or SsoAdvanced Universal SYBR Green Supermix, and a CFX96 Real-Time PCR Detection System (all from Bio-Rad Laboratories). PCR probes and primers were purchased from Life Technologies. Specific PCR 
primers for human and rat target genes were designed on sequences available at the National Center for Biotechnology Information GenBank (https://www.ncbi. nlm.nih.gov/genbank/) or Ensemble Genome (http:// www.ensembl.org). The expression of $18 \mathrm{~S}$ ribosomal subunit was used as the reference gene for the relative quantization of the target genes based on the comparative threshold cycle $2^{-\Delta \Delta C t}$ method (Livak \& Schmittgen 2001).

\section{Results}

\section{mRNA expression of sex steroid receptors in human and rat vaginal tissues}

Figure 1 shows the mRNA expression of $A R$ as compared to the other sex steroid receptors in human (panel A) and rat (panel B) distal vagina tissues, by using realtime RT-PCR. In both human (panel A) and rat (panel B) vaginal tissue, $A R$ mRNA shows an almost three log unit higher expression as compared to estrogen receptor $\beta$ $(E R \beta, P<0.001)$ and G-protein coupled estrogen receptor 1 (GPER1, $P<0.001$ ), reaching an expression level that is of the same order of magnitude of the estrogen receptor $\alpha$ $(E R \alpha)$, although slightly lower $(E R \alpha, P<0.01$ and $P<0.05$ vs human and rat $A R$, respectively). $A R$ expression was significantly higher than that one of progesterone receptor $(P R)$, but only in human vagina $(P<0.001$, panel A). We then evaluated the expression of $A R$ as compared to the other sex steroids receptors in hvSMCs and rvSMCs (Fig. 1 , panels $\mathrm{C}$ and $\mathrm{D}$, respectively). In hvSMCs, $A R$ resulted the most expressed receptor among other sex steroid, receptor, including $E R \alpha, E R \beta, G P E R 1$ and $P R$ (all $P<0.001$;
Fig. 1, panel C). A similar figure was observed in rvSMCs, although, in these cells, $\mathrm{Ar}$ was less expressed than $\mathrm{Pr}$ $(P<0.05$; Fig. 1, panel D).

\section{Characterization of smooth muscle cells from human (hvSMCs) and rat (rvSMCs) vagina}

Human vaginal smooth muscle cells (hvSMCs) showed a high positive staining for the specific smooth muscle markers myosin heavy chain 11 , MHC11 (91.5 $\pm 6.2 \%$; Fig. 2, panel A) and for the $\alpha$ smooth muscle actin, $\alpha \mathrm{SMA}$ (100\%; Fig. 2, panel B), while resulting negative for epithelial marker cytokeratin (Fig. 2, panel C). Rat vaginal smooth muscle cells (rvSMCs) showed a similar pattern of markers expression, with a high positive immunostaining for both smooth muscle markers (MHC11: $94.5 \pm 4.4 \%$, Fig. 2, panel D; $\alpha$ SMA: $90.2 \pm 4.3 \%$, Fig. 2, panel E), and negative staining for the epithelial marker cytokeratin (Fig. 2, panel F).

Figure 2 (panels $\mathrm{G}$ and I) shows representative images for nuclear immunostaining of AR in hvSMCs and rvSMCs, respectively, while panels $\mathrm{H}$ and $\mathrm{J}$ show the corresponding nuclear DAPI counterstaining. The quantification of cellular nuclear positivity was performed by counting positive nuclei for AR, and in both SMCs the positivity was $100 \%$.

\section{Toll-like receptors (TLRs) mRNA expression pattern in hvSMCs and rvSMCs}

To evaluate the potential contribution of vagina SMCs to the inflammatory process, we assessed the membrane
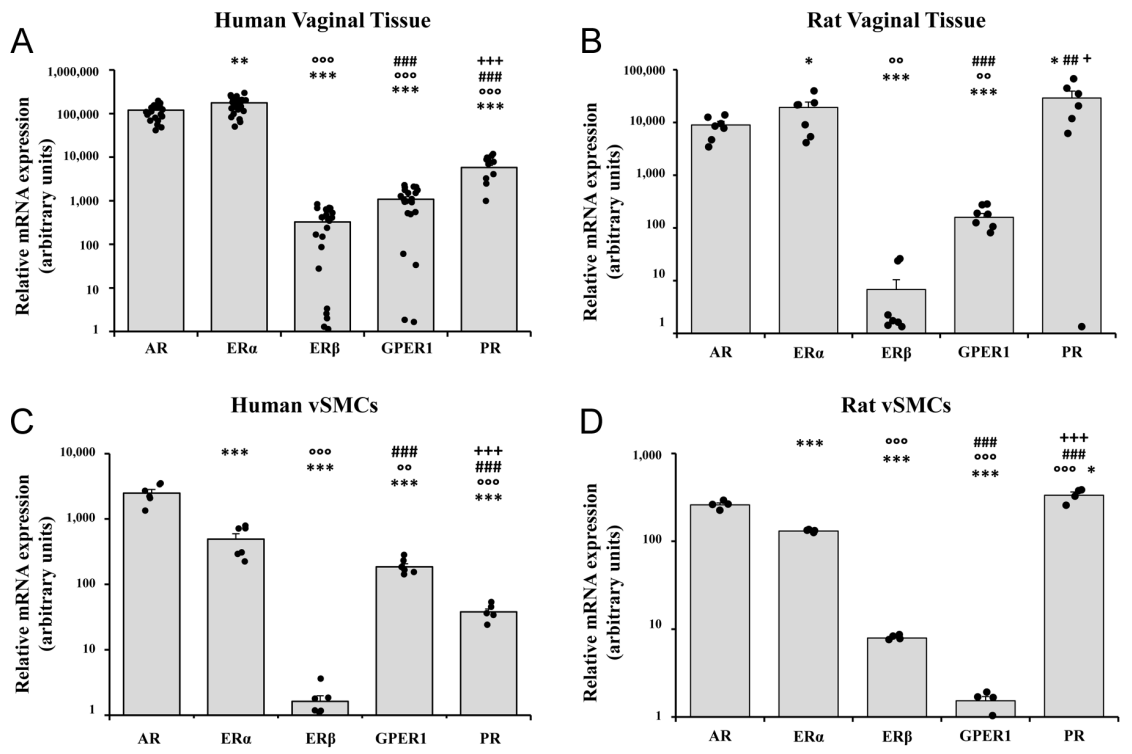

D

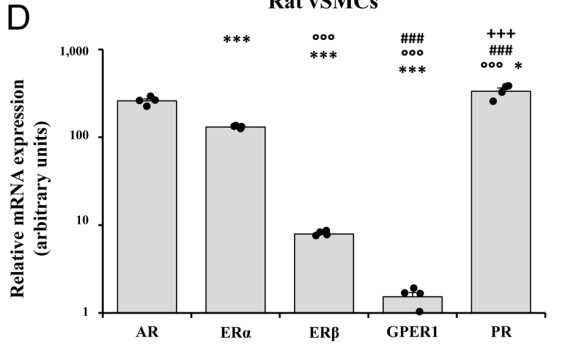

Figure 1

mRNA expression of sex steroid receptors in human and rat distal vagina tissues cells. Panels $A$ and $B$ show the mRNA expression, reported as scatter plot and bar graph, of sex steroid receptors $A R, E R \alpha, E R \beta, G P E R 1$ and $P R$ in human and rat distal vagina tissues, the former derived from laparoscopic biopsies, respectively. Panels C and D show the mRNA expression of sex steroid receptors $A r, E r \alpha, E r \beta, G p e r 1$ and Pr in human distal vagina and in rat distal vagina SMCs, respectively. Data were calculated according to the $2^{-\Delta \Delta \mathrm{t} t}$ comparative method, using ribosomal subunit $18 \mathrm{~S}$ as the reference gene for normalization $(* P<0.05$,

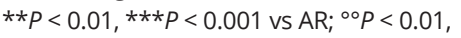
${ }^{\circ \circ} P<0.001$ vs $E R \alpha$; $\# \#<0.01, \# \# P<0.001$ vs ER $\beta$; $+P<0.05,{ }^{++} P<0.001$ vs GPER 1 ). 


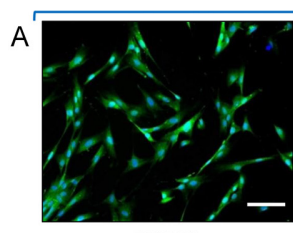

MHC11

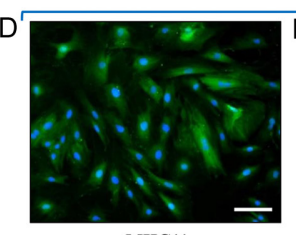

MHC11

Human vSMCs

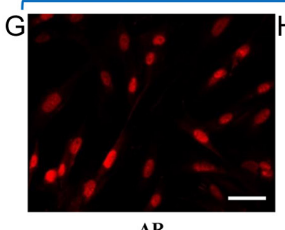

AR

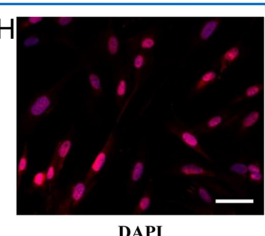

DAPI

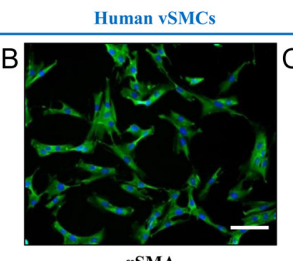

aSMA

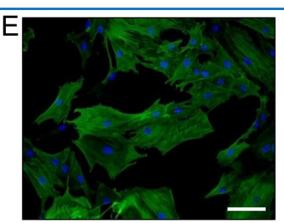

aSMA
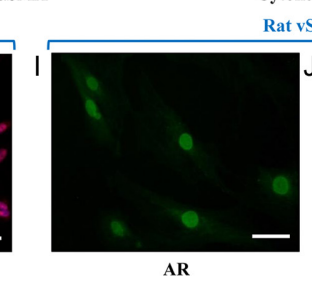

profile of toll-like receptors (TLRs), by using real-time RT-PCR for hvSMCs and rvSMCs (Fig. 3, panels A and $\mathrm{B}$, respectively). In hvSMCs, we also compared the pattern of TLRs mRNA expression to that of primary cell lines isolated from benign prostatic hyperplasia (hBPH) samples, a well-validated model of non-professional APCs that constitutively expressed all TLRs ( Penna et al. 2009) (Fig. 3, panel A). hvSMCs expressed all TLRs, with TLR1, TLR2, TLR3, and TLR4 being the most abundant. The mRNA expression profile presented by hvSMCs was rather similar to that of hBPH cells. In particular, hvSMCs showed a significantly higher expression of TLR2 $(P<0.001), T L R 5$ $(P<0.001)$ and TLR9 $(P<0.01)$, and a significantly lower expression of TLR1 $(P<0.001)$, TLR3 $(P<0.001)$ and TLR6

\section{Figure 2}

Characterization of SMCs isolated from human and rat vagina tissues. Panels $A, B$ and $C$ show the results of hvSMCs immunostaining for specific smooth muscle markers MHC11 and $\alpha \mathrm{SMA}$, and for epithelial marker cytokeratin (taken as negative control), respectively. Panels D-F show the results of rvSMCs immunostaining for specific smooth muscle markers MHC11 and $\alpha \mathrm{SMA}$, and for epithelial marker cytokeratin (taken as negative control), respectively. The quantitative analysis was performed by counting positive cells in at least 10 fields per slide of three different cell preparations (scale bar $=100 \mu \mathrm{m}$ ). Panels $\mathrm{G}$ and $\mathrm{H}$ show two representative images of hvSMCs nuclear immunostaining for AR receptor and the corresponding nuclear DAPI double labeling, respectively (scale bar $=50 \mu \mathrm{m})$. Similarly, panels I and J show two representative images of rvSMCs nuclear immunostaining for AR receptor and the corresponding nuclear DAPI double labeling, respectively (scale bar $=50 \mu \mathrm{m}$ ). A full color version of this figure is available at https://doi. org/10.1530/JME-20-0147.
$(P<0.01)$, when compared to hBPH cells (Fig. 3, panel A). Similarly, rvSMCs expressed all TLRs, with a relatively higher level of transcripts encoding Tlr1, Tlr2, Tlr3, Tlr4 and $\operatorname{Tlr} 10$ (Fig. 3, panel B).

\section{Treatment with the selective AR agonist,} dihydrotestosterone (DHT) inhibits basal and LPS-induced mRNA expression and secretion of pro-inflammatory mediators in hvSMCs

Under basal (untreated, NT) conditions, hvSMCs produced several cytokines, chemokines, and growth factors in the culture medium (Fig. 4). Among these factors, MCP1 was the most abundantly secreted, followed from, by at

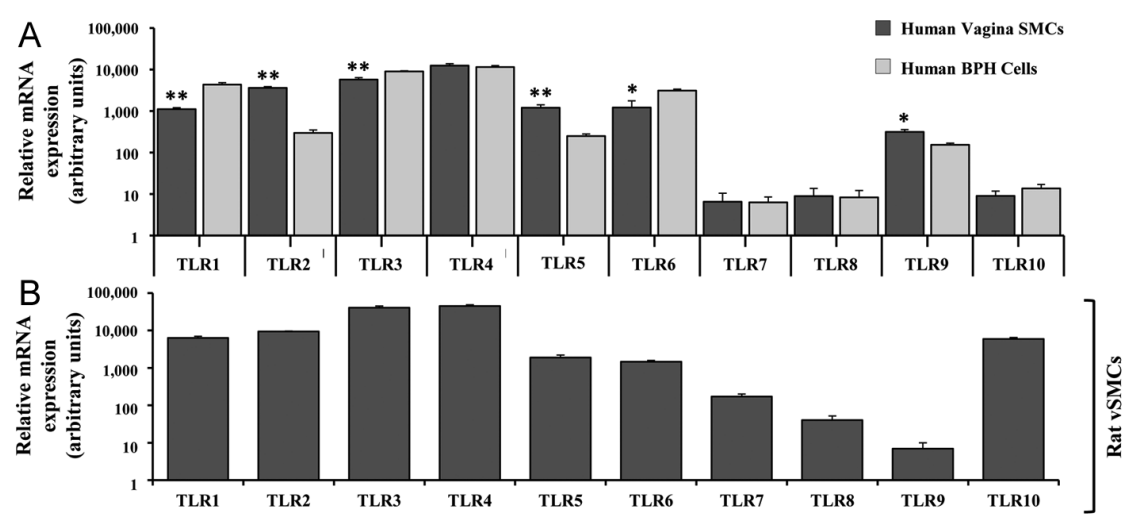

\section{Figure 3}

Toll-like receptors (TLRs) mRNA expression pattern and anti-inflammatory effect of DHT in vSMCs. Panel A shows the complete panel of the TLRs mRNA expression in hvSMCs, with the relative $T L R$ s gene expression in human $\mathrm{BPH}$ cells taken as positive control. The results were calculated according to the 2 - $\Delta \Delta \mathrm{ct}$ comparative method, using the ribosomal subunit 185 as the reference gene for normalization, and data are represented as the mean \pm S.E.M. of three independent experiments $(* P<0.01, * * P<0.001$ vs hBPHs). Panel B shows the complete panel of TIrs mRNA expression in rvSMCs. Data were calculated according to the $2^{-\Delta \Delta c t}$ comparative method, using the ribosomal subunit $18 \mathrm{~S}$ as the reference gene for normalization and are represented as the mean \pm S.E.M. of three independent experiments. 


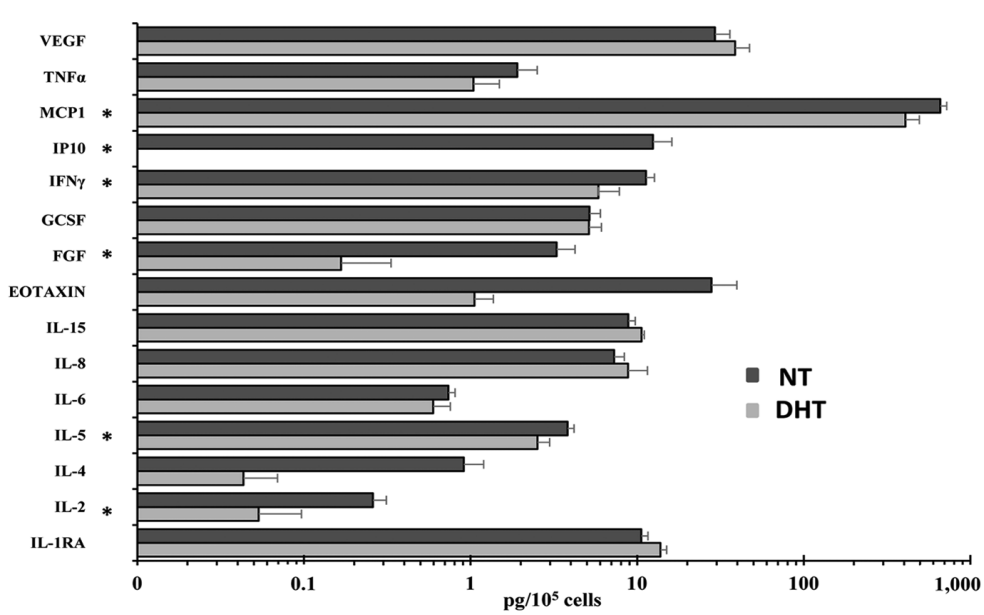

\begin{tabular}{|c|c|c|}
\hline & $\begin{array}{c}\mathbf{N T} \\
\left(\mathbf{p g} / \mathbf{1 0}^{5} \text { cells }\right)\end{array}$ & $\begin{array}{c}\text { DHT } \\
\left(\mathbf{p g} / \mathbf{1 0}^{5} \text { cells }\right)\end{array}$ \\
\hline VEGF & $29.32 \pm 6.75$ & $38.66 \pm 8.64$ \\
\hline TNF $\boldsymbol{\alpha}$ & $1.91 \pm 0.60$ & $1.04 \pm 0.45$ \\
\hline MCP1 & $659.85 \pm 62.56$ & $407.85 \pm 86.15^{*}$ \\
\hline IP10 & $12.44 \pm 3.74$ & $0.00^{*}$ \\
\hline IFN $\gamma$ & $11.28 \pm 1.42$ & $5.86 \pm 1.95^{*}$ \\
\hline GCSF & $5.18 \pm 0.85$ & $5.14 \pm 0.96$ \\
\hline FGF & $3.28 \pm 0.96$ & $0.17 \pm 0.17^{*}$ \\
\hline EOTAXIN & $27.97 \pm 11.65$ & $1.06 \pm 0.31$ \\
\hline IL-15 & $8.85 \pm 0.90$ & $10.62 \pm 0.39$ \\
\hline IL-8 & $7.28 \pm 1.09$ & $8.81 \pm 2.73$ \\
\hline IL-6 & $0.74 \pm 0.07$ & $0.60 \pm 0.16$ \\
\hline IL-5 & $3.82 \pm 0.36$ & $2.52 \pm 0.46^{*}$ \\
\hline IL-4 & $0.91 \pm 0.29$ & $0.04 \pm 0.03$ \\
\hline IL-2 & $0.26 \pm 0.05$ & $0.05 \pm 0.04^{*}$ \\
\hline IL-1RA & $10.58 \pm 1.04$ & $13.78 \pm 1.25$ \\
\hline & & \\
\hline
\end{tabular}

\section{Figure 4}

The effect of DHT pre-treatment on basal production of pro-inflammatory cytokines, chemokines, and growth factors in hvSMCs culture supernatant. The data represent the mean \pm S.E.M. of three independent experimental points performed in triplicate ( ${ }^{*} P<0.05$ vs NT). The numerical values expressed as pg/105 cells for each cytokine/chemokine are reported in the Table.

least one log unit, VEGF, eotaxin, IP10 and IFNy (Fig. 4). Interestingly, pre-treatment with the selective AR ligand dihydrotestosterone (DHT) significantly blunted basal secretion of MCP1, also significantly inhibiting IP10, IFN $\gamma$, FGF, IL-5 and IL-2 basal secretion (Fig. 4).
We next evaluated the effect of DHT (30 $\mathrm{nM}$ for $24 \mathrm{~h}$ ), with or without the non-steroidal AR antagonist bicalutamide (1 $\mu \mathrm{M}$ for $24 \mathrm{~h}$ ), on LPS-stimulated cytokine production in hvSMCs (Fig. 5, panels A-K). LPS $(100 \mathrm{ng} / \mathrm{mL}$ for $24 \mathrm{~h})$ significantly increased the secretion
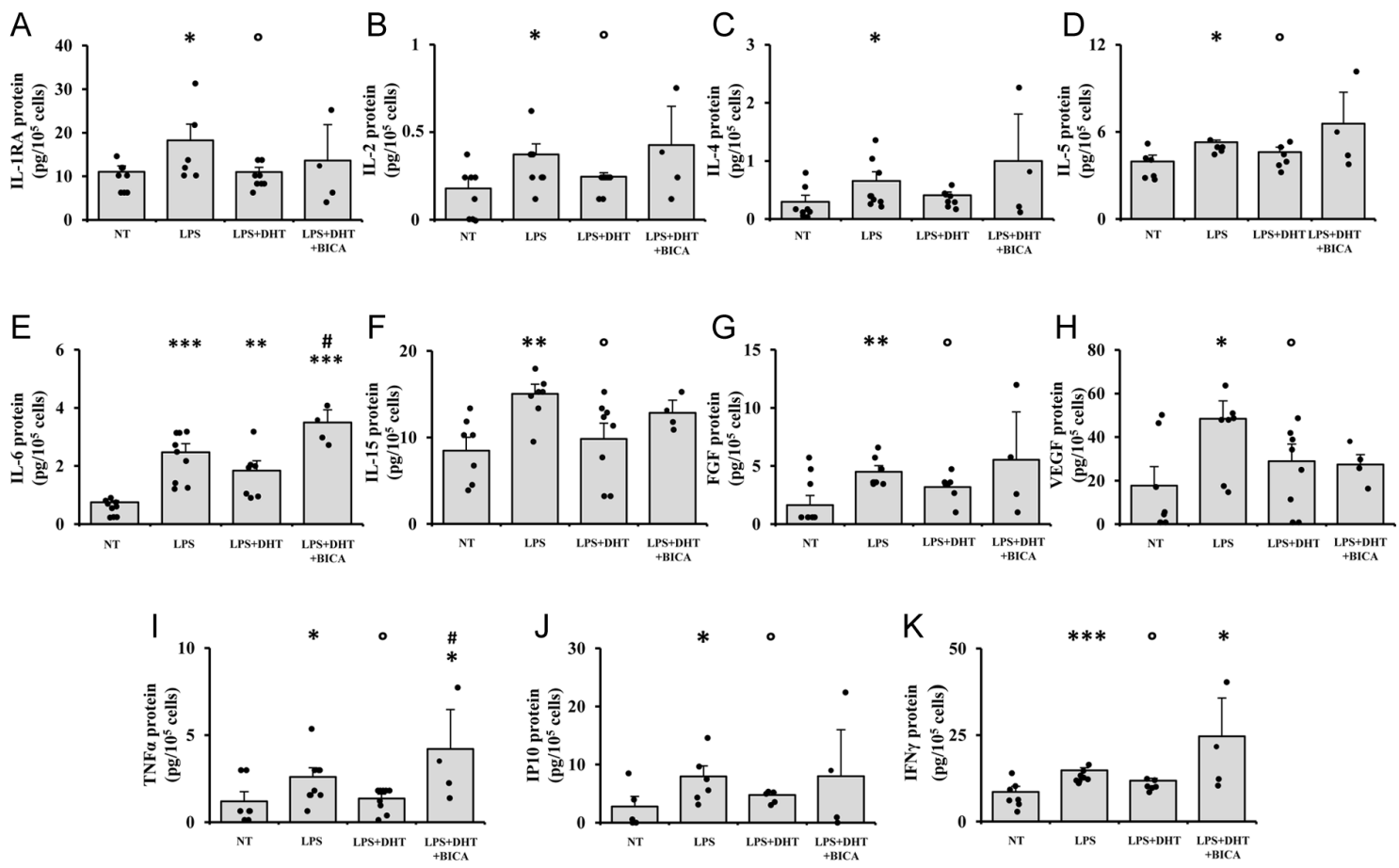

Figure 5

DHT effects on secretion of pro-inflammatory mediators in LPS-stimulated vaginal hSMCs. The hvSMC supernatants from each experimental point were analyzed for the production of the indicated proinflammatory cytokines, chemokines, and growth factors (panels A-K). The data represent the mean \pm S.E.M. of three independent experiments performed in triplicate and are reported as scatter plot and bar graph $(* P<0.05, * \star P<0.01, \star \star \star * P<0.001$ vs NT; ${ }^{\circ} P<0.05$ vs LPS; $\# P<0.05$ vs LPS + DHT). 

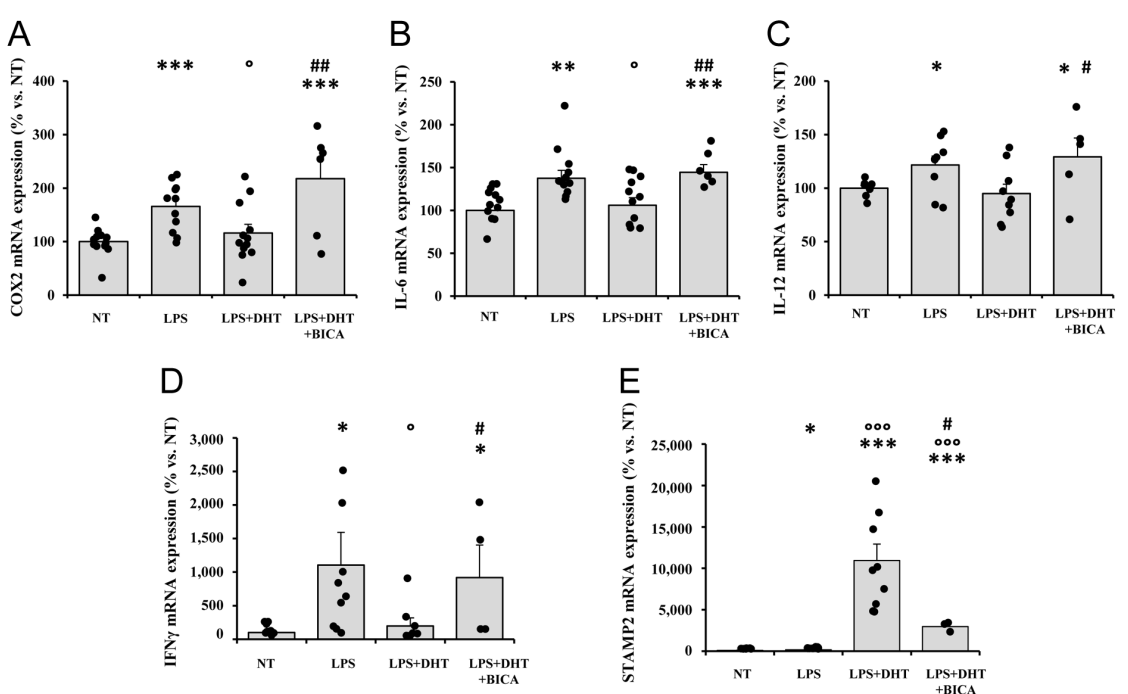

\section{Figure 6}

DHT effects on mRNA expression of proinflammatory mediators in LPS-stimulated hvSMCs. Human vaginal SMCs were left untreated (NT) or stimulated with LPS, in the presence or absence of DHT pre-incubation (30 nM for $24 \mathrm{~h}$ ), in combination or not with BICA (1 $\mu \mathrm{M}$ for $24 \mathrm{~h})$. The mRNA expression of pro-inflammatory markers COX2, IL-6, IL-12 and IFN $\gamma$ are shown in panels A-D, respectively, whereas antiinflammatory and androgen-sensitive STAMP2 mRNA expression is shown in panel E. Data were calculated according to 2- $\Delta \Delta \mathrm{Ct}$ comparative method, using $18 \mathrm{~S}$ ribosomal subunit as reference gene for normalization. Results are expressed as percentage of NT and are reported as mean \pm S.E.M. of three independent experiments performed in triplicate and are reported as scatter plot and bar graph $(* P<0.05$, $\star \star * P<0.01, * * \star P<0.001$ vs NT; ${ }^{\circ} P<0.05$, ${ }^{000} P<0.001$ vs LPS; $\# P<0.05, \# P<0.01$ vS LPS + DHT). of several pro-inflammatory proteins, including IL-2, IL-4, IL-5, VEGF, TNF $\alpha$, IP10 (all $P<0.05$ vs NT), IL-15 and FGF (both $P<0.01$ vs NT), IL-6 $(P<0.001$ vs NT) and, most importantly, IFN $\gamma(P<0.001$ vs NT), while inducing a slight increase of the anti-inflammatory protein IL-1RA $(P<0.05$ vs NT). Pre-treatment with DHT significantly counteracted the secretion of IFN $\gamma(P<0.05$ vs LPS; Fig. 5, panel K), along with IL-2, IL-5, IL-15, FGF, VEGF, TNF $\alpha$, and IP10 (all $P<0.05$ vs LPS; Fig. 5, panels B, D, F, G, H, $\mathrm{I}, \mathrm{J}$, respectively), but not IL-6, for which DHT induces a decrease in secretion to the limit of significance $(P=0.09$ vs LPS; Fig 5, panel E). A significant reduction of the antiinflammatory cytokine IL-1RA was also observed (Fig. 5, panel A). Co-treatment of DHT with bicalutamide tended to counteract most of the effects of DHT on LPS-stimulated secretions (Fig. 5, panels A-K). In particular, TNF $\alpha$ and IFN $\gamma$ were significantly increased by bicalutamide co-treatment, reaching a level even significantly higher than NT (Fig. 5, panels I and K, respectively), whereas VEGF secretion was unchanged by bicalutamide co-treatment (Fig. 5, panel H). Secretion of IL-8, GCSF, GMCSF, MCP1 and MIP1B was also significantly increased by LPS-treatment (all $P<0.05$ vs NT), but neither DHT nor bicalutamide were able to affect it (data not shown).

As shown in Fig. 6 (panels A-D), LPS also significantly upregulated the mRNA expression of the inducible form of cyclooxygenase-2 (COX2; $P<0.001$ vs NT), along with other inflammatory factors, namely $I L-6(P<0.01$ vs NT), IL-12 $(P<0.05$ vs NT), and $I F N \gamma$ $(P<0.05$ vs NT). The expression of all these genes was significantly reduced by pre-treatment with DHT (all $P<0.05$ vs LPS; Fig. 6, panels A-D), and co-treatment with bicalutamide completely blunted the DHT-induced effects $(P<0.01$ vs LPS+DHT for COX 2 and $I L-6, P<0.05$ vs LPS+DHT for $I L-12$ and IFN $\gamma$; Fig. 6, panels A-D). DHT treatment also significantly upregulated the mRNA expression of the anti-inflammatory, and androgensensitive, gene STAMP2 $(P<0.001$ vs both NT and LPS), which was also stimulated by LPS, but to a much lower extent $(P<0.05$ vs NT) (Fig. 6, panel E). Co-treatment with bicalutamide robustly counteracted DHT-induced STAMP2 upregulation $(P<0.05$ vs LPS+DHT; Fig. 6, panel E).

\section{DHT inhibits NF-кB p65 nuclear translocation in LPS-stimulated hvSMCs}

To better characterize the effect of DHT on the inflammatory response in LPS-stimulated hvSMCs, we evaluated nuclear translocation of NF-кB p65 by immunofluorescence (Fig. 7, panels A-E). In untreated (NT) hvSMCs, NF-кB p65 was only detected within the cytoplasm (Fig. 7, panels A and E), while LPS treatment induced a significant increase of its translocation to nuclei $(21.6 \pm 1.8 \% ; P<0.001$ vs NT; Fig. 7, panels B and E). Co-treatment with DHT significantly blunted LPS-induced nuclear translocation of NF-кB p65, without normalizing it $(11.8 \pm 1.3 \% ; P<0.001$ vs LPS; $P<0.001$ vs NT; Fig. 7, panels C and E). Co-treatment with bicalutamide ( $1 \mu \mathrm{M}$ for $24 \mathrm{~h}$ ) significantly counteracted DHT effect $(25.5 \pm 2.1 \% ; P<0.01$ vs LPS+DHT; Fig. 7 , panels $\mathrm{D}$ and $\mathrm{E})$. 
A

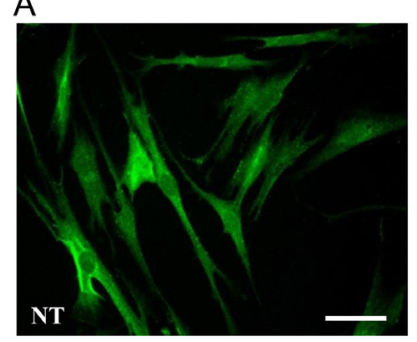

B
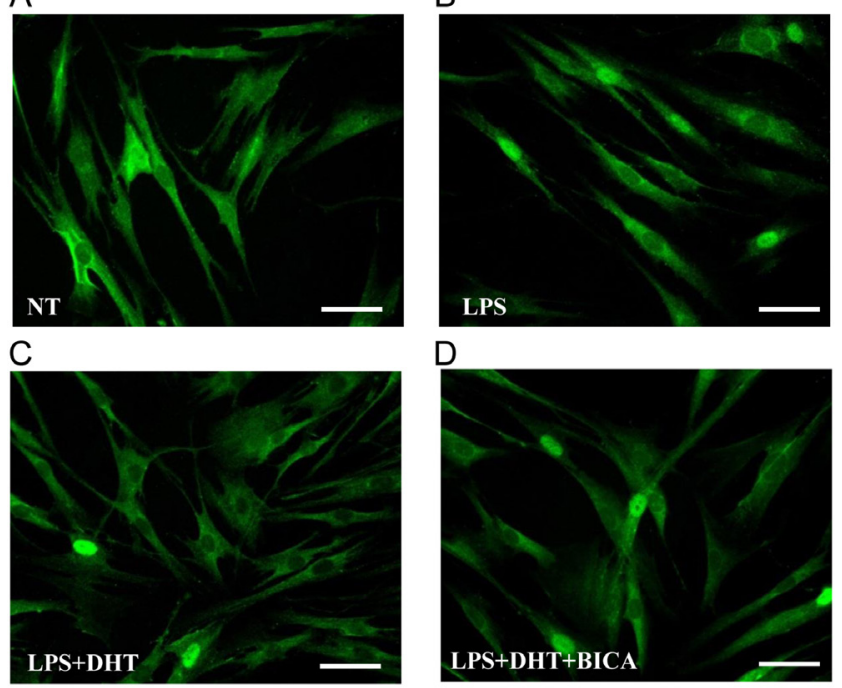

D

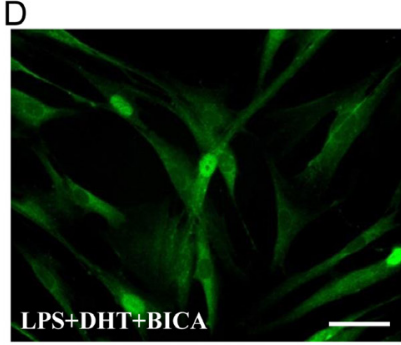

$\mathrm{E}$

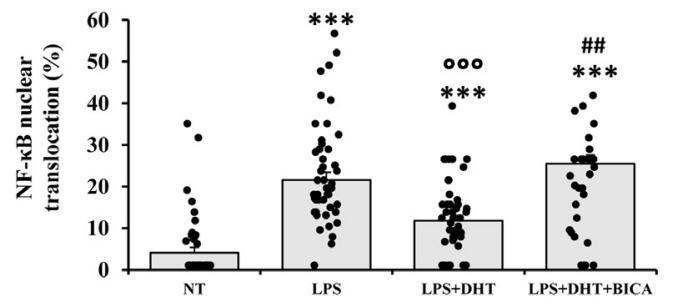

Figure 7

DHT effects on NF-kB p65 nuclear translocation in LPS-stimulated hvSMCs. Vaginal hSMCs were left untreated (NT) or stimulated with LPS (100 ng/mL) for $5 \mathrm{~h}$, with or without pre-treatment with DHT (30 nM for $24 \mathrm{~h})$, in combination or not with BICA (1 $\mu \mathrm{M}$ for $24 \mathrm{~h})$. The NF-кB p65 nuclear translocation was analyzed by immunofluorescence and representative images of NF- $\mathrm{KB}$ immunostaining of three experiments are shown in panels A-D for NT, LPS, LPS + DHT and LPS + DHT + BICA experimental groups, respectively (scale bar $=100 \mu \mathrm{m}$ ). Panel $\mathrm{E}$ bar graph shows the quantitative analysis of NF-кB nuclear translocation (evaluated in at least in 10 fields per slide), expressed as the number of positive cells as percentage of total cells. The data represent the mean \pm S.E.M. of three independent experiments performed in triplicate and are reported as scatter plot and bar graph ( $* * * P<0.001$ vs NT; ${ }^{\circ 00} P<0.001$ vs LPS; $\# \# P<0.01$ vs LPS + DHT). A full color version of this figure is available at https://doi.org/10.1530/JME-20-0147.

\section{Treatment with DHT inhibits IFN $\gamma$-induced mRNA expression and secretion of pro-inflammatory mediators in hvSMCs}

We tested the effect of the Th1 driven inflammatory cytokine, IFN $\gamma$, on hvSMCs. Stimulation with IFN $\gamma$ (1000 IU/mL for $24 \mathrm{~h}$ ) significantly increased the mRNA expression of several inflammatory factors such as iNOS, COX2, MCP1 and $I L-12$ (all $P<0.001$ vs NT; Fig. 8, panels A-D). In particular, IFN $\gamma$ induced a $\sim 3-\log$ unit increase of IP10 mRNA expression ( $P<0.001$ vs NT; Fig. 8, panel E). All these effects were significantly blunted by DHT pretreatment (all $P<0.05$ vs IFN $\gamma$; Fig. 8, panels A-E).
Figure 9 (panels A-F) shows that IFN $\gamma$ stimulation (1000 IU/mL for $24 \mathrm{~h}$ ) increased the secretion of several pro-inflammatory chemokines and cytokines (IL-1 $\beta$, IL-2, IL-5, IL-6, MCP1 and GCSF, all $P<0.001$ vs NT), and DHT pre-treatment (30 nM for $24 \mathrm{~h}$ ) partially blunted it (all $P<0.05$ vs IFN $\gamma$ ). Interestingly, DHT pre-treatment also reduced, even though without reaching statistical significance, IFN $\gamma$-stimulated secretion of TNF $\alpha$, VEGF, FGF and IL-17 (data not shown). Finally, IFN $\gamma$ induced a significant increase in the secretion of IL-1RA, IL-4, IL-7, IL-9, IL-12, IL-13, IL-15, IP10, MIP1A, MIP1B and RANTES; however, no significant effects were observed in their levels after DHT pre-treatment (data not shown).

\section{Evaluation of the effects of IFN $\gamma$ and DHT on the HLA-DR expression in hvSMCs}

We next evaluated the effect of IFN $\gamma$ (1000 UI/mL for 48 h) with or without DHT pre-treatment on the expression of class II histocompatibility (HLA-DR) antigens on the cell surface of hvSMCs, assessed by using flow cytometry (Fig. 9, panel G). As expected, HLA-DR was not expressed in NT and DHT only-treated cells, whereas its expression was significantly increased $(47.5 \pm 5.5 \% ; P<0.001$ vs NT) after IFN $\gamma$ stimulation (Fig. 9, panels G and H). Pretreatment with DHT significantly decreased IFN $\gamma$-induced HLA-DR expression (37.6 $\pm 1.3 \% ; P<0.01$ vs IFN $\gamma$ ), albeit without normalizing it $(P<0.001$ vs NT) (Fig. 9, panels $G$ and $\mathrm{H})$.

\section{Anti-inflammatory effect of the selective AR agonist, dihydrotestosterone (DHT) in rvSMCs}

Some of the experiments performed in hvSMCs were repeated in rvSMCs. The effect of DHT (30 nM for $24 \mathrm{~h}$ ), in presence or absence of bicalutamide ( $1 \mu \mathrm{M}$ for $24 \mathrm{~h}$ ), was assessed in rvSMCs, under basal (Fig. 10, panels A-F) and after LPS-stimulated condition (Fig. 10, panels G-J). DHT significantly inhibited the basal mRNA expression of the proinflammatory markers $I l-6(P<0.01$ vs NT), Cxcl1 $(P<0.001$ vs NT), Mcp1 $(P<0.05$ vs NT) and Cox $2(P<0.001$ vs NT) (Fig. 10, panels A, B, D and E, respectively), while significantly increasing the mRNA expression of the antiinflammatory and androgen-dependent factor Stamp2 $(P<0.01$ vs NT; Fig. 10, panel F). In most but not all cases, DHT effect was blunted by co-treatment with bicalutamide $(P<0.05$ vs DHT for $I l-6$ and Mcp1; $P<0.001$ vs DHT for Cox2; Fig. 10, panels A, D and E, respectively).

We also evaluated the effect of increasing concentrations of DHT on rvSMCs stimulated by 

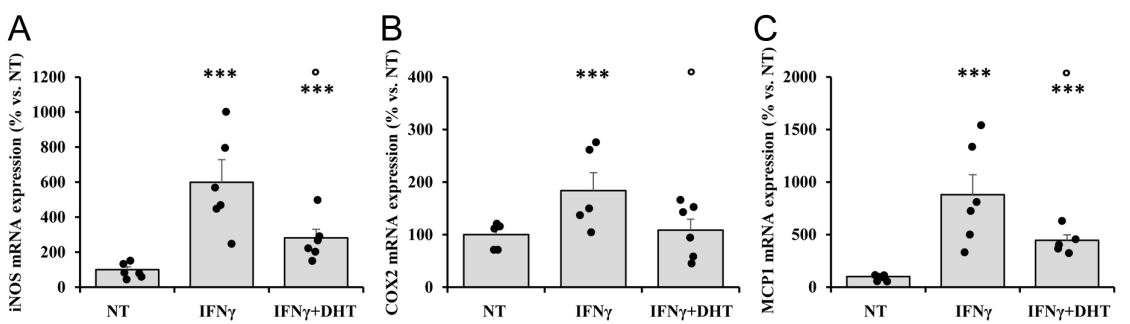

\section{Figure 8}

DHT effects on mRNA expression of proinflammatory mediators in INF $\gamma$-stimulated hvSMCs. Panels A-E report the mRNA expression analysis of pro-inflammatory cytokines and chemokines after hvSMC cells were stimulated with IFN $\gamma(1000 \mathrm{IU} / \mathrm{mL})$ for $24 \mathrm{~h}$, with or without
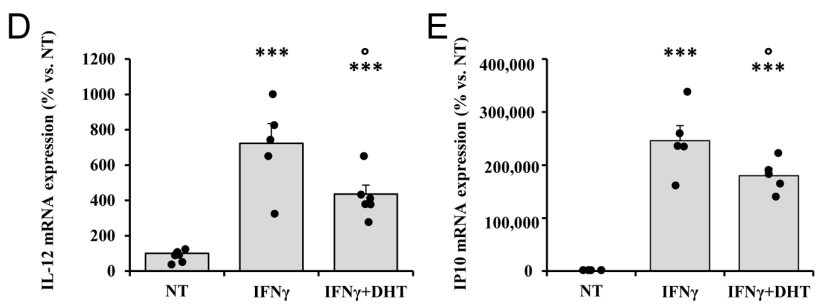

DHT incubation (30 nM, 24 h). Data were calculated according to $2-\Delta \Delta \mathrm{ct}$ comparative method, using $18 \mathrm{~S}$ ribosomal subunit as reference gene for normalization. Results are expressed as percentage of untreated cells (NT) and are reported as mean \pm S.E.M. of three independent experiments performed in triplicate and are reported as scatter plot and bar graph $\left(* \star * P<0.001\right.$ vs NT; ${ }^{\circ} P<0.05$ vs IFN $\gamma$ ).

LPS (Fig. 10, panel G). Increasing concentrations of DHT (ranging from $10 \mathrm{pM}$ to $1 \mu \mathrm{M}$ ) significantly blunted LPS-induced Il-6 and Cxcl1 mRNA expression in a dose-dependent manner with a similar $\mathrm{IC}_{50}$ $\left(\mathrm{IC}_{50}=5.1 \times 10^{-10} \mathrm{M}\right.$ for $\mathrm{Il}-6$, and $\mathrm{IC}_{50}=5.6 \times 10^{-10} \mathrm{M}$ for Cxcl1) and maximum inhibitory effect $\left(\mathrm{I}_{\max }=82.1 \pm 9 \%\right.$ for Il-6, and $\mathrm{I}_{\max }=78.2 \pm 7.2 \%$ for Cxcl1; Fig. 10, panel G). In addition, LPS induced the mRNA expression of other pro-inflammatory mediators, namely $\mathrm{Il}-1 \beta, M c p 1$ (both $P<0.001$ vs NT; Fig. 10, panels $\mathrm{H}$ and I, respectively) and $\operatorname{Cox} 2(P<0.01$ vs NT; Fig. 10, panel J). LPS effects were significantly blunted by DHT (all $P<0.05$ vs LPS;
A
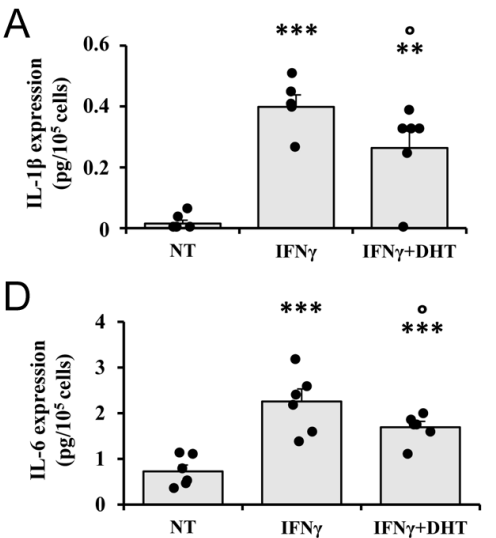

G
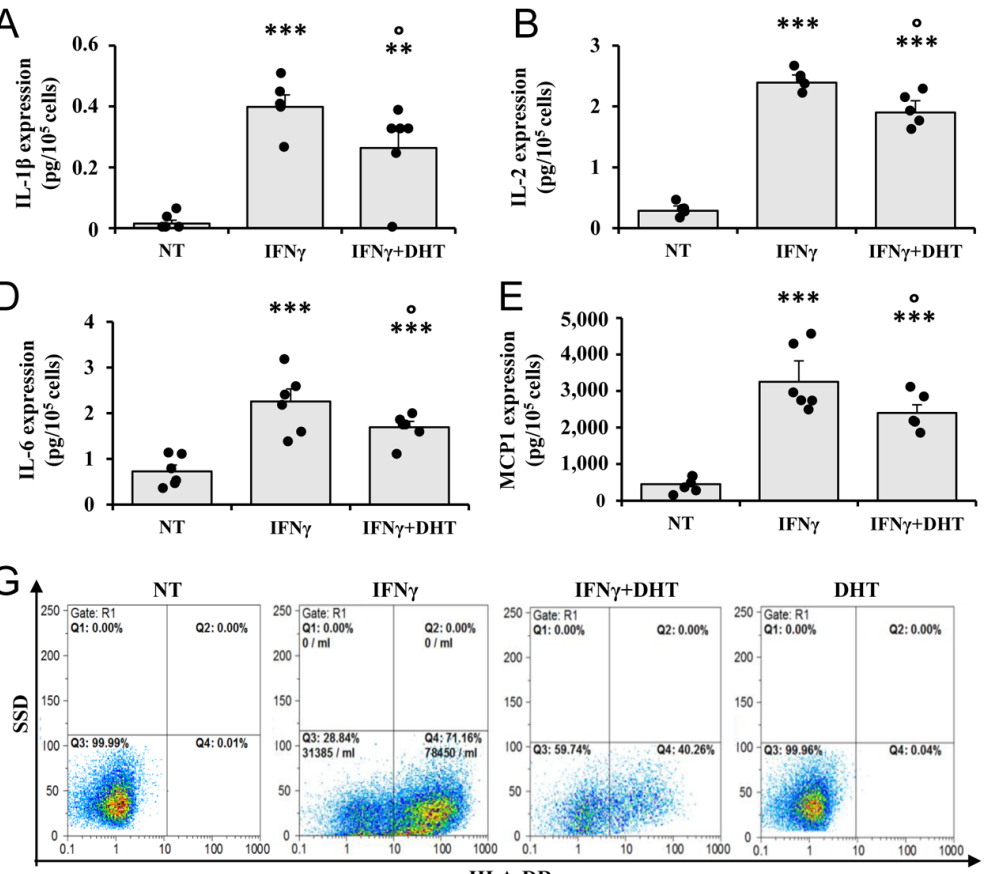
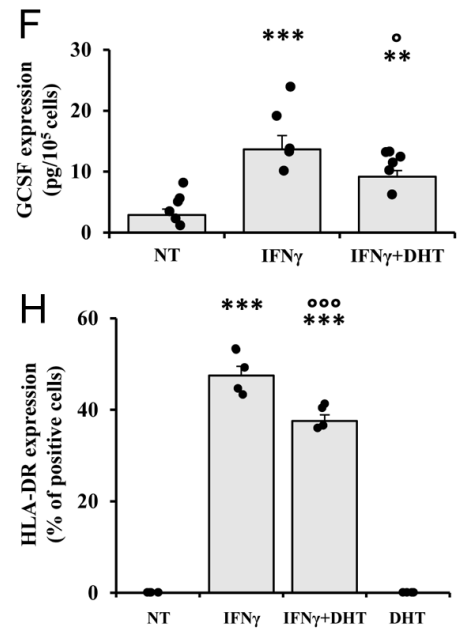

\section{Figure 9}

DHT effects on the secretion of pro-inflammatory mediators and on the cell surface HLA-DR expression in IFN $\gamma$-stimulated hvSMCs. Vaginal hSMCs supernatants from each experimental point were analyzed for the secretion of pro-inflammatory cytokines, chemokines and growth factors (panels A-F). Data are represented as the mean \pm S.E.M. of three independent experiments performed in triplicate and are reported as scatter plot and bar graph $\left(* \star P<0.01,{ }^{*} * P<0.001\right.$ vs NT; ${ }^{\circ} P<0.05$ vs IFN $\gamma$ ). Panel G reports the results of a representative experiment of flow cytometry showing the expression of HLA-DR in hvSMCs stimulated with IFN $\gamma(1000 \mathrm{IU} / \mathrm{mL}$ ) for $48 \mathrm{~h}$ and/or of DHT treatment ( $30 \mathrm{nM}$, for $24 \mathrm{~h}$ ). Panel H shows the quantification of cell positivity for HLA-DR, expressed as percentage of positive cells compared to the total number of cells. Data are reported as mean \pm S.E.M. of three

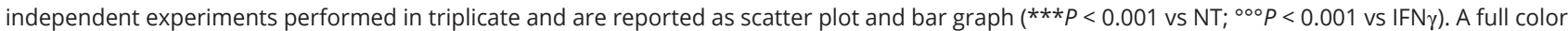
version of this figure is available at https://doi.org/10.1530/JME-20-0147. 
A
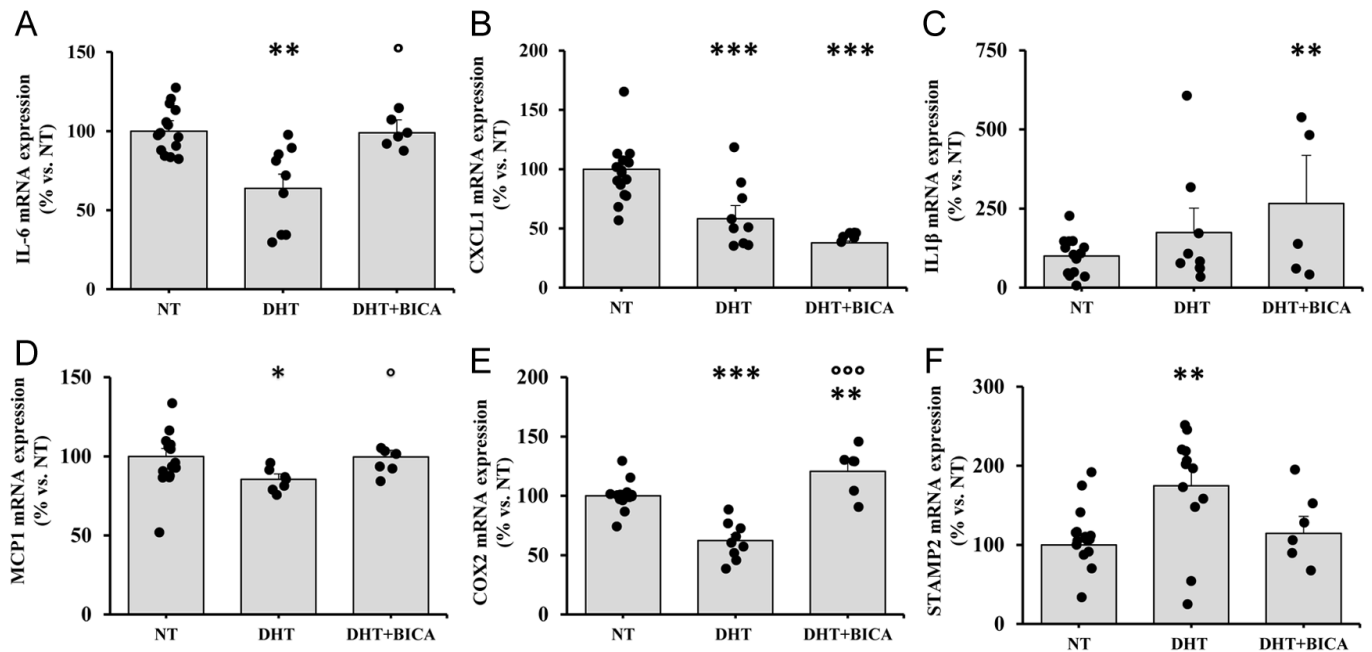
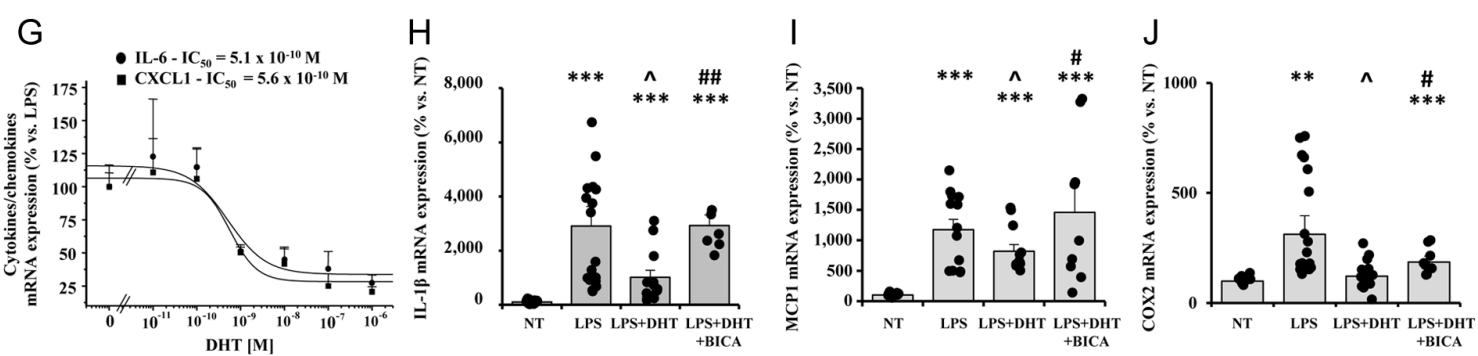

\section{Figure 10}

DHT effects on basal and LPS-induced mRNA expression of proinflammatory and androgen-dependent markers in rvSMCs. Rat vaginal SMCs were cultured for $24 \mathrm{~h}$ in serum-free medium alone (untreated cells, NT) or DHT (30 nM), with or without anti-androgen bicalutamide (BICA, $1 \mu \mathrm{M})$ or were stimulated with LPS (100 ng/mL for $24 \mathrm{~h}$ ), with or without pre-incubation with DHT and in the presence or absence of BICA The mRNA expression of pro-inflammatory (II-6, CxCl1, II-1B, Mcp1, Cox2) and androgen-dependent (Stamp2) markers after pre-incubation with DHT in combination or not with bicalutamide is showed in panels A-F. Panel G shows the inhibitory effect of increasing concentrations of DHT on LPS-induced mRNA expression of II-6 and $\mathrm{Cx} / 1$ in rVSMCs. Ordinate: mRNA expression of the indicated pro-inflammatory factors (black square: $\mathrm{CxCl1}$; black circle: II-6) induced by LPS after DHT pre-incubation. Data are expressed as percentage of the effect of LPS alone. Abscissa: molar concentrations of DHT (10 pM-1 $\mu$ M). Data are represented as the mean \pm S.E.M. of three independent experiments performed in triplicate and are reported as scatter plot and bar graph. The relative half-maximal response $\left(\mathrm{IC}_{50}\right)$ value is reported in the graph. Panels $\mathrm{H}-\mathrm{J}$ show the mRNA expression of pro-inflammatory markers $I I-1 \beta, M c p 1, \mathrm{Cox2}$, induced by LPS stimulation alone and after pre-incubation with DHT, in combination or not with bicalutamide. Data were calculated according to the 2- $\Delta \Delta \mathrm{Ct}$ comparative method, using the $18 \mathrm{~S}$ ribosomal subunit as the reference gene for normalization. The results represent the mean \pm S.E.M. of three independent experiments, performed in triplicate and reported as percentage vs untreated cells (NT) $\left(* P<0.05, * * P<0.01, * * * P<0.001\right.$ vs NT; ${ }^{\circ} P<0.05$, ${ }^{000} P<0.001$ vs DHT, $\wedge P<0.05$ vs LPS; $\# P<0.05, \# P<0.01$ vs LPS + DHT).

Fig. 10, panels H-J), while co-treatment with bicalutamide completely abolished the inhibitory effects of DHT $(P<0.01$ vs LPS+DHT for Il-1 $\beta, P<0.05$ vs LPS+DHT for Mcp1 and Cox2; Fig. 10, panels H, I and J, respectively).

\section{DHT inhibits NF- $\mathrm{kB}$ p65 nuclear translocation in LPS-stimulated rvSMCs}

Immunofluorescence analyses for NF-kB p65 nuclear translocation in rvSMCs are shown in Fig. 11 (panels A-E). Similarly to hvSMCs, in untreated (NT) rvSMCs, NF-кB p65 was detected only within the cytoplasm (Fig. 11, panels A and E). LPS stimulation (100 $\mathrm{ng} / \mathrm{mL}$ for $5 \mathrm{~h}$ ) induced a partial but significant translocation of NF-kB p65 to the nucleus $(40.2 \pm 2.2 \% ; P<0.001$ vs NT; Fig. 11 , panels B and E), which was significantly inhibited $(20.8 \pm 1.9 \%$; $P<0.001$ vs LPS), albeit not normalized $(P<0.001$ vs NT), by DHT treatment (Fig. 11, panels $\mathrm{C}$ and E). Co-treatment with bicalutamide $(1 \mu \mathrm{M}$ for $24 \mathrm{~h})$ partially contrasted DHT-induced effect $(31.3 \pm 2.3 \% ; P<0.05$ vs LPS; $P<0.01$ vs LPS+DHT; Fig. 11, panels D and E).

\section{Discussion}

The present study demonstrates, for the first time, that human vagina smooth muscle cells (hvSMCs) might be actively involved in the inflammatory response, since they express all TLRs and secrete several pro-inflammatory factors upon stimulation with LPS - used to mimic an infectious-driven inflammation - and IFN $\gamma$ - used to 
A

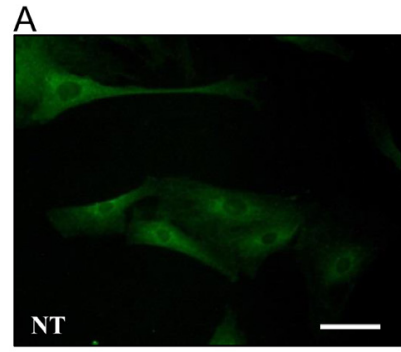

B

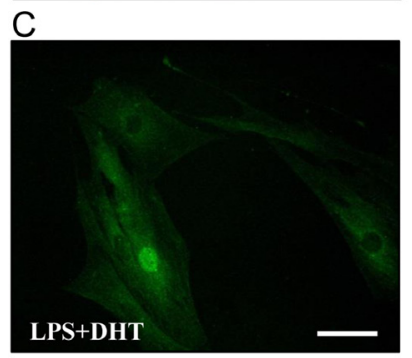

LPS

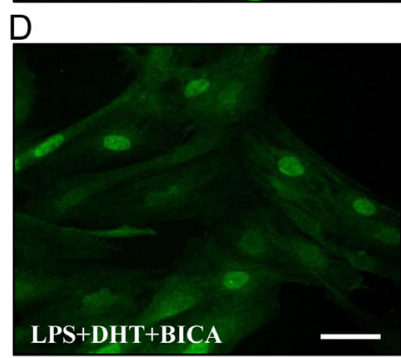

E

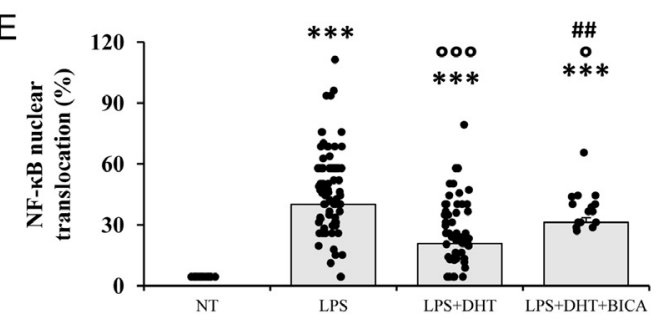

\section{Figure 11}

DHT effects on LPS-induced NF-kB p65 nuclear translocation in rvSMCs. Rat vaginal SMC cells were stimulated with LPS (100 ng/mL for $5 \mathrm{~h}$ ) with or without pre-incubation with DHT ( $30 \mathrm{nM}$ for $24 \mathrm{~h}$ ), in combination or not with BICA ( $1 \mu \mathrm{M}$ for $24 \mathrm{~h}$ ). The NF-kB p65 activation in rvSMCs was quantified by immunofluorescence analysis. The representative images in panels A-D show the results of NF-kB immunostaining in each experimental group (scale bar $=50 \mu \mathrm{m}$ ). In panel $\mathrm{E}$, the bar graph reports the number of cells with NF-kB nuclear positivity (evaluated in at least in 10 fields per slide), expressed as percentage of total cells. The data represent the mean \pm S.E.M. of three independent experiments performed in triplicate and are reported as scatter plot and bar graph ( $* \star \star P<0.001$ vs NT; ${ }^{\circ} P<0.05,{ }^{\circ 00} P<0.001$ vs LPS; $\# P<0.01$ vs LPS + DHT). A full color version of this figure is available at https://doi.org/10.1530/JME-20-0147.

mimic a Th1-driven immune response. The hvSMCs were indeed able to respond to LPS by secreting several cytokines and chemokines, including those related to the Th1-chronic immune response such as IFN $\gamma$, IP10, IL-2, IL-12, and IL-15 (Lees 2015). Stimulation of hvSMCs with IFN $\gamma$, in turn, substantially increased the production of several inflammatory agents and induced the expression of HLA-DR on hvSMCs surface. De novo expression of HLA-DR, a particular human leukocyte antigens (HLA) molecule that is unknown in conventional SMCs (Erokhina et al. 2018), indicated that, under inflammatory conditions, hvSMCs acquire the ability to take part in antigen presentation and in persistent chronic inflammation. More importantly, we also found that
hvSMCs expressed high levels of AR, through which DHT counteracts either LPS- or IFN $\gamma$-induced inflammation by blunting the expression and secretion of inflammatory factors, including IFN $\gamma$ itself and IP10, the two most important Th1-cytokines (Dufour et al. 2002). DHT also significantly counteracted IFN $\gamma$-induced expression of HLA-DR on the cell surface. These findings, derived from a large set of in vitro experiments, consistently indicated that hvSMCs might behave as resident nonprofessional APCs that, after an acute bacterial infection (experimentally mimicked by LPS stimulation), promote a Th1-polarized immune response and chronicity (Rose 2001). Noteworthy, the activation of AR by DHT exerts a relevant anti-inflammatory effect by blunting the ability of hvSMCs to respond to inflammatory stimuli and to perpetuate inflammation. Accordingly, similar antiinflammatory effects had been previously demonstrated in male prostatic tissue (Vignozzi et al. 2012a, 2013a). Even though some subtle differences were observed, the similarities of results obtained in rat and human vagina smooth muscle suggest that both the ability of vSMCs to take part to the inflammatory response and the anti-inflammatory role of DHT are, most likely, not species-specific.

Inflammation usually represents the main immune system's defense to harmful stimuli, aimed at removing pathogenic noxae and at restoring tissue homeostasis (Chen et al. 2017b). Under most conditions, APCs play a relevant role in the local immune surveillance by allowing the host to distinguish between self- vs non-self, as well as pathogenic vs commensal bacteria (Medzhitov 2001). However, in some conditions, an exacerbated activation of APCs, which continues even after the removal of pathogenic microorganisms, polarizes lymphocytes toward a Th1 phenotype, with the consequent production of the Th1 cell-specific cytokines (i.e. IFN $\gamma$ ) (Chen et al. $2017 b$ ). This process leads to the break in the tolerance to self-antigens and to a progression from an acute toward a chronic immune-mediated local disease (Chen et al. 2017b). Noteworthy, these events have been also crucially involved in the development of many diseases of female genitourinary tract, including dyspareunia (Farage et al. 2008), vulvodynia (Zanotta et al. 2018), vestibulodynia (Tommola et al. 2016), endometriosis (Symons et al. 2018), as well as cystitis (Singh et al. 2013).

On the other hand, both animal and human studies have been extensively documenting that androgens act as important anti-inflammatory factors (Gilliver 2010). With regard to genitourinary tissue in males, we previously demonstrated the ability of human prostatic stromal 
cells (hBPH cells) to act as non-professional APCs, and to actively contribute to intraprostatic chronic inflammatory diseases (Penna et al. 2009, Vignozzi et al. 2012a, 2013a). In this model, we showed a prominent anti-inflammatory effect of the AR agonist DHT in inhibiting the potential of hBPHs to induce and sustain inflammatory responses (Vignozzi et al. 2012a). Although emerging literature suggested that androgen-dependent pathway(s) might be involved in the resolution of genitourinary conditions in women, such as the GSM (Simon et al. 2018), immunomodulatory effects of androgen signaling in the vagina was not investigated so far.

Therefore, in the first set of experiments, we isolated and characterized SMCs derived from human and rat vagina, to ascertain potential species-specific biological effects. Both hvSMCs and rvSMCs lines express all sex steroids receptors, with an overall abundance of AR. In particular, in isolated hvSMCs, $A R$ resulted the most expressed receptor, with mRNA expression levels significantly higher as compared to $E R \alpha, E R \beta$, GPER 1 and PR. In contrast, when the human vaginal tissue homogenates was analyzed, $A R$ was abundantly expressed, but reaching a level significantly lower than $E R \alpha$. A similar pattern of expression was also observed in rvSMCs and rat vaginal tissue. Accordingly, previous immunohistochemistry analyses in the monkey and rat vagina demonstrated that the highest proportion of AR-immunoreactive cells occurred in the muscularis and lamina propria (Pessina et al. 2006, Bertin et al. 2014), whereas ER $\alpha$ and PR seem to be mostly expressed in the epithelium (Pessina et al. 2006). This is consistent with the fact that, in our study, AR resulted less expressed than ER $\alpha$ and PR when analyzing the whole tissue, which obviously includes all the other cellular components such as the epithelial one.

Noteworthy, either hvSMCs or rvSMCs also expressed all identified TLRs, with hvSMCs showing a similar expression pattern to that found in hBPHs, a wellvalidated non-professional APCs (Penna et al. 2009), thus indicating that also hvSMCs might have the ability to initiate and coordinate an acute reaction to pathogens. TLR1-4 emerged as the most expressed, with TLR2 being found at even higher level than in hBPHs. TLR4 is considered a crucial defense against not only viruses and protozoa, but also bacteria, thanks to its binding to LPS of Gram-negative species (Nasu \& Narahara 2010). TLR2 also recognizes several key molecules on the surface of pathogens, such as LPS, or lipoproteins and peptidoglycans that are commonly released during genital tract infections (Shey et al. 2016).
We also demonstrated that, in basal conditions, hvSMCs secrete several proinflammatory and growth factors, including MCP1, VEGF, eotaxin, IL-8, IL-15, IP10 and IFN $\gamma$. Pre-treatment with the potent and selective AR agonist DHT markedly reduced this basal secretion. In addition, we tested the effect of DHT in hvSMCs triggered by two canonical inflammatory stimuli: LPS, used to mimic an infection (Rusek et al. 2018), and IFN $\gamma$, used to simulate a chronic and self-perpetuating inflammation (Hamidzadeh et al. 2017). After LPS stimuli, hvSMCs increased the secretion of acute (i.e. IL-2, IL-4, IL-5, IL-15, TNF $\alpha$ and IL-1RA) and Th1-related cytokines (i.e. IFN $\gamma$ and IP10), along with growth factors (FGF and VEGF). DHT significantly counteracted the effects of LPS, restoring cytokines secretion down to basal levels. Pre-treatment with DHT significantly decreased also LPSinduced mRNA expression of inflammatory genes such as COX2, IL-6, IL-12A and IFN $\gamma$, while upregulating the anti-inflammatory and androgen-sensitive gene STAMP2. Co-treatment with the AR antagonist bicalutamide was able to dampen almost all these effects, thus indicating that the observed anti-inflammatory activity of DHT was mainly mediated by AR. Interestingly, bicalutamide did not significantly antagonize the effect of DHT on VEGF secretion. This could be explained with the fact that bicalutamide has been reported to be ineffective in blocking non-genomic activation of the AR, and that non-genomic signaling of the AR is involved in a positive modulation of proliferation (Leung \& Sadar 2017). The anti-inflammatory effect of DHT on IFN $\gamma$ secretion is of particular relevance, since IFN $\gamma$ is the most potent Th1cytokine (Liblau et al. 1995), and its signaling plays a key role in development of autoimmunity and chronic, selfperpetuating inflammatory diseases (Chen et al. 2017a). In rvSMCs, we found similar anti-inflammatory effects of DHT on LPS-induced cytokines and chemokines mRNA expression and secretion into the media. Noteworthy, in this cell culture, increasing concentrations of DHT exerted a dose-dependent reduction of LPS-induced cytokines and chemokines' expression with an $\mathrm{IC}_{50} \sim 0.5 \mathrm{nM}$, a value close to the physiological concentrations of DHT in women (Rothman et al. 2011).

The mechanisms by which androgen signaling exerts its anti-inflammatory effects are not completely understood. In previous studies in human BPH cells, we demonstrated that DHT inhibits nuclear translocation and activation of NF- $\mathrm{kB}$, a master transcription factor in inflammation (Tak \& Firestein 2001, Vignozzi et al. 2012a). The same effect was also described in a modified adipocyte chronic inflammation model 
(Morooka et al. 2016). Similarly, in the present study, inhibition of LPS-induced nuclear translocation of NF-кB by DHT was detected in both rvSMCs and hvSMCs.

The effect of DHT was also tested after treatment of vSMCs with IFN $\gamma$. Pre-treatment with DHT counteracted IFN $\gamma$-induced mRNA expression of iNOS, COX2, MCP1, $I L-12$ and IP10, which are all involved in amplifying and sustaining inflammatory states (Barrios-Rodiles et al. 1999, Proost et al. 2003, Mitchell et al. 2012, Steinman 2013, Lees 2015). In particular, IP10 is a main driver toward chronic inflammatory diseases and tissue remodeling (Neville et al. 1997). DHT also significantly counteracted IFN $\gamma$-induced secretion of cytokines, chemokines and growth factors (IL-1 $\beta$, IL-2, IL-5, IL-6, MCP1 and GCSF) in hvSMCs, as well as blunted IFN $\gamma$-induced de novo expression of HLA-DR on hvSMCs' surface. Overexpression of HLA-DR that occurs on non-inflammatory cells is one of the main pathogenic mechanisms observed in autoimmune diseases (Bottazzo et al. 1983, Jacobson et al. 2008). Our observations that HLA-DR may be experimentally induced on hvSMCs indicate their capacity to present autoantigens to $\mathrm{T}$ lymphocytes. It is conceivable that, after the first phases of the host reaction (mimicked by LPS stimulation), the consequent production of Th1 cytokines, including IFN $\gamma$, might lead to de novo expression of HLA-DR on vaginal SMCs, thus enhancing their ability to perpetuate inflammation. This could be the underpinning mechanism of an organ-specific chronic, self-perpetuating inflammation in the human vagina, where infections easily initiate (Monin et al. 2020).

The GSM results from the complex interplay among decreased sex steroids levels and age-related systemic chronic inflammation ('Inflamm-aging') and changes in the immune response (Gameiro et al. 2010, Klein \& Flanagan 2016, Simon et al. 2018). We here propose a novel immunoregulatory role played by androgens in the GSM and in other chronic inflammatory diseases affecting women's genital tract. The immunosuppressive role of androgens on key components of both innate and adaptive immunity has been consistently described in recent literature in pre-clinical and clinical models in males (Vignozzi et al. 2012a,b,c, Trigunaite et al. 2015). In particular, in vitro testosterone treatment of isolated mouse macrophages elicited a decrease in TLR4 expression and in sensitivity to a specific ligand (Rettew et al. 2008). In vitro treatment with androgens also resulted in inhibition of Th1 differentiation and less IFN $\gamma$ production by the peripheral $\mathrm{T}$ cell population (Kissick et al. 2014). Noteworthy, in experimental animal model of metabolic syndrome-associated systemic low-grade inflammation, testosterone treatment exerted a potent anti-inflammatory action in several districts, including liver (Vignozzi et al. 2014), adipose tissue (Maneschi et al . 2012), bladder (Morelli et al. 2012) and prostate (Vignozzi et al. 2012b). Our data are consistent with this view and appear innovative in that, for the first time, expand the paradigm of the anti-inflammatory effects of androgens to females and specifically to the vagina.

In conclusion, our data suggest that vaginal SMCs have the ability to be involved in the immune response, acting as non-professional APCs, and that the activation of AR exerts an important anti-inflammatory activity by inhibiting their role in inducing and/or sustaining immune and inflammatory responses. Androgens represent a potential therapeutic strategy for the GSM, to be further investigated in clinical studies.

\section{Declaration of interest}

The authors declare that there is no conflict of interest that could be perceived as prejudicing the impartiality of the research reported.

\section{Funding}

This research was supported by a PRIN grant ('Progetti di Rilevante Interesse Nazionale': 2017S9KTNE) and a 2018 International Society for the Study of Women's Sexual Health (ISSWSH) Research Grant.

\section{References}

Barrios-Rodiles M, Tiraloche G \& Chadee K 1999 Lipopolysaccharide modulates cyclooxygenase- 2 transcriptionally and posttranscriptionally in human macrophages independently from endogenous IL-1 $\beta$ and TNF- $\alpha$. Journal of Immunology 163 963-969.

Bertin J, Dury AY, Ouellet J, Pelletier G \& Labrie F 2014 Localization of the androgen-synthesizing enzymes, androgen receptor, and sex steroids in the vagina: possible implications for the treatment of postmenopausal sexual dysfunction. Journal of Sexual Medicine $\mathbf{1 1}$ 1949-1961. (https://doi.org/10.1111/jsm.12589)

Bottazzo GF, Pujol-Borrell R, Hanafusa T \& Feldmann M 1983 Role of aberrant HLA-DR expression and antigen presentation in induction of endocrine autoimmunity. Lancet 2 1115-1119. (https://doi. org/10.1016/s0140-6736(83)90629-3)

Chen K, Liu J \& Cao X $2017 a$ Regulation of type I interferon signaling in immunity and inflammation: a comprehensive review. Journal of Autoimmunity 83 1-11. (https://doi.org/10.1016/j.jaut.2017.03.008)

Chen L, Deng H, Cui H, Fang J, Zuo Z, Deng J, Li Y, Wang X \& Zhao L $2017 b$ Inflammatory responses and inflammation-associated diseases in organs. Oncotarget 9 7204-7218. (https://doi.org/10.18632/ oncotarget.23208)

Comeglio P, Morelli A, Cellai I, Vignozzi L, Sarchielli E, Filippi S, Maneschi E, Corcetto F, Corno C, Gacci M, et al. 2014 Opposite effects of tamoxifen on metabolic syndrome-induced bladder and prostate alterations: a role for GPR30/GPER? Prostate 74 10-28. (https://doi.org/10.1002/pros.22723)

Comeglio P, Cellai I, Filippi S, Corno C, Corcetto F, Morelli A, Maneschi E, Maseroli E, Mannucci E, Fambrini M, et al. 2016 
Differential effects of testosterone and estradiol on clitoral function: an experimental study in rats. Journal of Sexual Medicine $\mathbf{1 3}$ 1858-1871. (https://doi.org/10.1016/j.jsxm.2016.10.007)

Cunha GR, Kurita T, Cao M, Shen J, Robboy S \& Baskin L 2017 Molecular mechanisms of development of the human fetal female reproductive tract. Differentiation: Research in Biological Diversity 97 54-72. (https://doi.org/10.1016/j.diff.2017.07.003)

Davison SL, Bell R, Donath S, Montalto JG \& Davis SR 2005 Androgen levels in adult females: changes with age, menopause, and oophorectomy. Journal of Clinical Endocrinology and Metabolism 90 3847-3853. (https://doi.org/10.1210/jc.2005-0212)

Dufour JH, Dziejman M, Liu MT, Leung JH, Lane TE \& Luster AD 2002 IFN-gamma-inducible protein 10 (IP-10; CXCL10)-deficient mice reveal a role for IP-10 in effector T cell generation and trafficking. Journal of Immunology 168 3195-3204. (https://doi.org/10.4049/ jimmunol.168.7.3195)

Erokhina SA, Streltsova MA, Kanevskiy LM, Telford WG, Sapozhnikov AM \& Kovalenko EI 2018 HLA-DR+ NK cells are mostly characterized by less mature phenotype and high functional activity. Immunology and Cell Biology 96 212-228. (https://doi.org/10.1111/imcb.1032)

Farage MA, Miller KW \& Ledger WJ 2008 Determining the cause of vulvovaginal symptoms. Obstetrical and Gynecological Survey 63 445-464. (https://doi.org/10.1097/OGX.0b013e318172ee25)

Fazeli A, Bruce C \& Anumba DO 2005 Characterization of toll-like receptors in the female reproductive tract in humans. Human Reproduction 20 1372-1378. (https://doi.org/10.1093/humrep/ deh775)

Fibbi B, Penna G, Morelli A, Adorini L \& Maggi M 2010 Chronic inflammation in the pathogenesis of benign prostatic hyperplasia. International Journal of Andrology 33 475-488. (https://doi. org/10.1111/j.1365-2605.2009.00972.x)

Gameiro CM, Romão F \& Castelo-Branco C 2010 Menopause and aging: changes in the immune system - a review. Maturitas 67 316-320. (https://doi.org/10.1016/j.maturitas.2010.08.003)

Gilliver SC 2010 Sex steroids as inflammatory regulators. Journal of Steroid Biochemistry and Molecular Biology 120 105-115. (https://doi. org/10.1016/j.jsbmb.2009.12.015)

Granchi S, Vannelli GB, Vignozzi L, Crescioli C, Ferruzzi P, Mancina R, Vinci MC, Forti G, Filippi S, Luconi M, et al. 2002 Expression and regulation of endothelin-1 and its receptors in human penile smooth muscle cells. Molecular Human Reproduction 8 1053-1064. (https:// doi.org/10.1093/molehr/8.12.1053)

Hamidzadeh K, Christensen SM, Dalby E, Chandrasekaran P \& Mosser DM 2017 Macrophages and the recovery from acute and chronic inflammation. Annual Review of Physiology 79 567-592. (https://doi.org/10.1146/annurev-physiol-022516-034348)

Jacobson EM, Huber A \& Tomer Y 2008 The HLA gene complex in thyroid autoimmunity: from epidemiology to etiology. Journal of Autoimmunity 30 58-62. (https://doi.org/10.1016/j.jaut.2007.11.010)

Kissick HT, Sanda MG, Dunn LK, Pellegrini KL, On ST, Noel JK \& Arredouani MS 2014 Androgens alter T-cell immunity by inhibiting T-helper 1 differentiation. PNAS 111 9887-9892. (https://doi. org/10.1073/pnas.1402468111)

Klein SL \& Flanagan KL 2016 Sex differences in immune responses. Nature Reviews: Immunology 16 626-638. (https://doi.org/10.1038/nri.2016.90)

Lees JR 2015 Interferon gamma in autoimmunity: a complicated player on a complex stage. Cytokine 74 18-26. (https://doi.org/10.1016/j. cyto.2014.10.014)

Leung JK \& Sadar MD 2017 Non-genomic actions of the androgen receptor in prostate cancer. Frontiers in Endocrinology 8 2. (https://doi. org/10.3389/fendo.2017.00002)

Liblau RS, Singer SM \& McDevitt HO 1995 Th1 and Th2 CD4+ T cells in the pathogenesis of organ-specific autoimmune diseases. Immunology Today 16 34-38. (https://doi.org/10.1016/01675699(95)80068-9)
Livak KJ \& Schmittgen TD 2001 Analysis of relative gene expression data using real-time quantitative PCR and the 2(-Delta Delta C(T)) method. Methods 25 402-408. (https://doi.org/10.1006/ meth.2001.1262)

Maneschi E, Morelli A, Filippi S, Cellai I, Comeglio P, Mazzanti B, Mello T, Calcagno A, Sarchielli E, Vignozzi L, et al. 2012 Testosterone treatment improves metabolic syndrome-induced adipose tissue derangements. Journal of Endocrinology 215 347-362. (https://doi. org/10.1530/JOE-12-0333)

Marks LS, Mazer NA, Mostaghel E, Hess DL, Dorey FJ, Epstein JI, Veltri RW, Makarov DV, Partin AW, Bostwick DG, et al. 2006 Effect of testosterone replacement therapy on prostate tissue in men with late-onset hypogonadism: a randomized controlled trial. JAMA 296 2351-2361. (https://doi.org/10.1001/jama.296.19.2351)

Medzhitov R 2001 Toll-like receptors and innate immunity. Nature Reviews: Immunology 1 135-145. (https://doi.org/10.1038/35100529)

Mitchell JE, Chetty S, Govender P, Pillay M, Jaggernath M, Kasmar A, Ndung'u T, Klenerman P, Walker BD \& Kasprowicz VO 2012 Prospective monitoring reveals dynamic levels of $\mathrm{T}$ cell immunity to Mycobacterium tuberculosis in HIV infected individuals. PLOS ONE 7 e37920. (https://doi.org/10.1371/journal.pone.0037920)

Monin L, Whettlock EM \& Male V 2020 Immune responses in the human female reproductive tract. Immunology 160 106-115. (https:// doi.org/10.1111/imm.13136)

Morelli A, Comeglio P, Filippi S, Sarchielli E, Cellai I, Vignozzi L, Yehiely-Cohen R, Maneschi E, Gacci M, Carini M, et al. 2012 Testosterone and farnesoid X receptor agonist INT-747 counteract high fat diet-induced bladder alterations in a rabbit model of metabolic syndrome. Journal of Steroid Biochemistry and Molecular Biology 132 80-92. (https://doi.org/10.1016/j.jsbmb.2012.02.007)

Morooka N, Ueguri K, Yee KKL, Yanase T \& Sato T 2016 Androgenandrogen receptor system improves chronic inflammatory conditions by suppressing monocyte chemoattractant protein- 1 gene expression in adipocytes via transcriptional regulation. Biochemical and Biophysical Research Communications 477 895-901. (https://doi. org/10.1016/j.bbrc.2016.06.155)

Nasu K \& Narahara H 2010 Pattern recognition via the toll-like receptor system in the human female genital tract. Mediators of Inflammation 2010 976024. (https://doi.org/10.1155/2010/976024)

Neville LF, Mathiak G \& Bagasra O 1997 The immunobiology of interferon-gamma inducible protein $10 \mathrm{kD}$ (IP-10): a novel, pleiotropic member of the C-X-C chemokine superfamily. Cytokine and Growth Factor Reviews 8 207-219. (https://doi.org/10.1016/s13596101(97)00015-4)

Penna G, Fibbi B, Amuchastegui S, Cossetti C, Aquilano F, Laverny G, Gacci M, Crescioli C, Maggi M \& Adorini L 2009 Human benign prostatic hyperplasia stromal cells as inducers and targets of chronic immuno-mediated inflammation. Journal of Immunology $\mathbf{1 8 2}$ 4056-4064. (https://doi.org/10.4049/jimmunol.0801875)

Pessina MA, Hoyt Jr RF, Goldstein I \& Traish AM 2006 Differential regulation of the expression of estrogen, progesterone, and androgen receptors by sex steroid hormones in the vagina: immunohistochemical studies. Journal of Sexual Medicine 3 804-814. (https://doi.org/10.1111/j.1743-6109.2006.00290.x)

Pivarcsi A, Nagy I, Koreck A, Kis K, Kenderessy-Szabo A, Szell M, Dobozy A \& Kemeny L 2005 Microbial compounds induce the expression of proinflammatory cytokines, chemokines and human beta-defensin-2 in vaginal epithelial cells. Microbes and Infection $\mathbf{7}$ 1117-1127. (https://doi.org/10.1016/j.micinf.2005.03.016)

Portman DJ, Gass ML \& Vulvovaginal Atrophy Terminology Consensus Conference Panel 2014 Genitourinary syndrome of menopause: new terminology for vulvovaginal atrophy from the International Society for the Study of Women's Sexual Health and the North American Menopause Society. Maturitas 79 349-354. (https://doi.org/10.1016/j. maturitas.2014.07.013) 
Proost P, Vynckier AK, Mahieu F, Put W, Grillet B, Struyf S, Wuyts A, Opdenakker G \& Van Damme J 2003 Microbial toll-like receptor ligands differentially regulate CXCL10/IP-10 expression in fibroblasts and mononuclear leukocytes in synergy with IFN-gamma and provide a mechanism for enhanced synovial chemokine levels in septic arthritis. European Journal of Immunology 33 3146-3153. (https://doi.org/10.1002/eji.200324136)

Rettew JA, Huet-Hudson YM \& Marriott I 2008 Testosterone reduces macrophage expression in the mouse of toll-like receptor 4 , a trigger for inflammation and innate immunity. Biology of Reproduction 78 432-437. (https://doi.org/10.1095/ biolreprod.107.063545)

Rose NR 2001 Infection, mimics, and autoimmune disease. Journal of Clinical Investigation 107 943-944. (https://doi.org/10.1172/ JCI12673)

Rothman MS, Carlson NE, Xu M, Wang C, Swerdloff R, Lee P, Goh VH, Ridgway EC \& Wierman ME 2011 Reexamination of testosterone, dihydrotestosterone, estradiol and estrone levels across the menstrual cycle and in postmenopausal women measured by liquid chromatography-tandem mass spectrometry. Steroids 76 177-182. (https://doi.org/10.1016/j.steroids.2010.10.010)

Rusek P, Wala M, Druszczyńska M \& Fol M 2018 Infectious agents as stimuli of trained innate immunity. International Journal of Molecular Sciences 19 E456. (https://doi.org/10.3390/ijms19020456)

Sarchielli E, Comeglio P, Filippi S, Cellai I, Guarnieri G, Guasti D, Rapizzi E, Rastrelli G, Bani D, Bianconi G, et al. 2020 Testosterone improves muscle fiber asset and exercise performance in a metabolic syndrome model. Journal of Endocrinology 245 259-279. (https://doi. org/10.1530/JOE-19-0532)

Shey MS, Maharaj N, Archary D, Ngcapu S, Garrett N, Abdool Karim S \& Passmore JA 2016 Modulation of female genital tract-derived dendritic cell migration and activation in response to inflammatory cytokines and toll-like receptor agonists. PLOS ONE 11 e0155668. (https://doi.org/10.1371/journal.pone.0155668)

Simon JA, Goldstein I, Kim NN, Davis SR, Kellogg-Spadt S, Lowenstein L, Pinkerton JV, Stuenkel CA, Traish AM, Archer DF, et al. 2018 The role of androgens in the treatment of genitourinary syndrome of menopause (GSM): International Society for the Study of Women's Sexual Health (ISSWSH) expert consensus panel review. Menopause 25 837-847. (https://doi.org/10.1097/GME.0000000000001138)

Singh UP, Singh NP, Guan H, Hegde VL, Price RL, Taub DD, Mishra MK, Nagarkatti M \& Nagarkatti PS 2013 The severity of experimental autoimmune cystitis can be ameliorated by anti-CXCL10 Ab treatment. PLOS ONE 8 e79751. (https://doi.org/10.1371/journal. pone.0079751)

Steinman L 2013 Inflammatory cytokines at the summits of pathological signal cascades in brain diseases. Science Signaling 6 pe3. (https://doi. org/10.1126/scisignal.2003898)

Symons LK, Miller JE, Kay VR, Marks RM, Liblik K, Koti M \& Tayade C 2018 The immunopathophysiology of endometriosis. Trends in Molecular Medicine 24 748-762. (https://doi.org/10.1016/j. molmed.2018.07.004)

Tak PP \& Firestein GS 2001 NF-kappaB: a key role in inflammatory diseases. Journal of Clinical Investigation 107 7-11. (https://doi. org/10.1172/JCI11830)

Tommola P, Unkila-Kallio L, Paetau A, Meri S, Kalso E \& Paavonen J 2016 Immune activation enhances epithelial nerve growth in provoked vestibulodynia. American Journal of Obstetrics and Gynecology 215 768.e1-768.e8. (https://doi.org/10.1016/j. ajog.2016.07.037)

Trigunaite A, Dimo J \& Jørgensen TN 2015 Suppressive effects of androgens on the immune system. Cellular Immunology 294 87-94. (https://doi.org/10.1016/j.cellimm.2015.02.004)

Urbani S, Caporale R, Lombardini L, Bosi A \& Saccardi R 2006 Use of CFDA-SE for evaluating the in vitro proliferation pattern of human mesenchymal stem cells. Cytotherapy 8 243-253. (https://doi. org/10.1080/14653240600735834)

Vignozzi L, Cellai I, Santi R, Lombardelli L, Morelli A, Comeglio P, Filippi S, Logiodice F, Carini M, Nesi G, et al. $2012 a$ Antiinflammatory effect of androgen receptor activation in human benign prostatic hyperplasia cells. Journal of Endocrinology 214 31-43. (https://doi.org/10.1530/JOE-12-0142)

Vignozzi L, Morelli A, Sarchielli E, Comeglio P, Filippi S, Cellai I, Maneschi E, Serni S, Gacci M, Carini M, et al. 2012b Testosterone protects from metabolic syndrome-associated prostate inflammation: an experimental study in rabbit. Journal of Endocrinology 212 71-84. (https://doi.org/10.1530/JOE-11-0289)

Vignozzi L, Filippi S, Morelli A, Comeglio P, Cellai I, Sarchielli E, Maneschi E, Mancina R, Gacci M, Vannelli GB, et al. 2012c Testosterone/estradiol ratio regulates NO-induced bladder relaxation and responsiveness to PDE5 inhibitors. Journal of Sexual Medicine 9 3028-3040. (https://doi.org/10.1111/j.1743-6109.2012.02946.x)

Vignozzi L, Morelli A, Corona G, Sebastianelli A, Serni S, Gacci M, Adorini L \& Maggi M 2012d Testosterone protects the lower urinary tract from metabolic syndrome-induced alterations. Hormone Molecular Biology and Clinical Investigation 11 329-337. (https://doi. org/10.1515/hmbci-2012-0029)

Vignozzi L, Gacci M, Cellai I, Morelli A, Maneschi E, Comeglio P, Santi R, Filippi S, Sebastianelli A, Nesi G, et al. 2013a PDE5 inhibitors blunt inflammation in human BPH: a potential mechanism of action for PDE5 inhibitors in LUTS. Prostate $\mathbf{7 3}$ 1391-1402. (https://doi.org/10.1002/pros.22686)

Vignozzi L, Gacci M, Cellai I, Santi R, Corona G, Morelli A, Rastrelli G, Comeglio P, Sebastanelli A, Maneschi E, et al. 2013b Fat boosts, while androgen receptor activation counteracts, BPH-associated prostate inflammation. Prostate 73 789-800. (https://doi.org/10.1002/ pros.22623)

Vignozzi L, Filippi S, Comeglio P, Cellai I, Sarchielli E, Morelli A, Rastrelli G, Maneschi E, Galli A, Vannelli GB, et al. 2014 Nonalcoholic steatohepatitis as a novel player in metabolic syndrome-induced erectile dysfunction: an experimental study in the rabbit. Molecular and Cellular Endocrinology 384 143-154. (https:// doi.org/10.1016/j.mce.2014.01.014)

Zanotta N, Campisciano G, Scrimin F, Ura B, Marcuzzi A, Vincenti E, Crovella S \& Comar M 2018 Cytokine profiles of women with vulvodynia: identification of a panel of pro-inflammatory molecular targets. European Journal of Obstetrics, Gynecology, and Reproductive Biology 226 66-70. (https://doi.org/10.1016/j.ejogrb.2018.05.035)

Zumoff B, Rosenfeld RS, Strain GW, Levin J \& Fukushima DK 1980 Sex differences in the twenty-four hour mean plasma concentrations of dehydroepiandrosterone (DHEA) and dehydroepiandrosterone sulfate (DHEA-S) and the DHEA to DHEAS ratio in normal adults. Journal of Clinical Endocrinology and Metabolism 51 330-333. (https://doi. org/10.1210/jcem-51-2-330)

Received in final form 24 July 2020

Accepted 4 August 2020

Accepted Manuscript published online 4 August 2020
(C) 2020 Society for Endocrinology Published by Bioscientifica Ltd. Printed in Great Britain 